Chemical Technology

Division

Chemical Technology

Division

Chemical Technology

Division

Chemical Technology

Division

Chemical Technology

Division

Chemical Technology

Division

Chemical Technology

Division

Chemical Technology

Division

Chemical Technology

Division

Chemical Technology

Division

Chemical Technology

Division

Chemical Technology

Division

Chemical Technology

Division

Chemical Technology

Division

Chemical Technology

Division

Chemical Technology

\section{Division}

Simulant Flowsheet Test with Modified Solvent for Cesium Removal Using Caustic-Side Solvent Extraction

by R. A. Leonard, S. B. Aase, H. A. Arafat, C. Conner, J. R. Falkenberg, M. C. Regalbuto, and G. F. Vandegrift

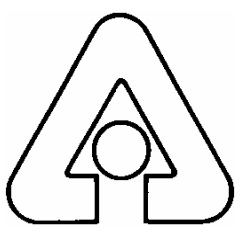

Argonne National Laboratory, Argonne, Illinois 60439

operated by The University of Chicago

for the United States Department of Energy under Contract W-31-109-Eng-38

Chemical Technology

Division

Chemical Technology

Division

Chemical Technology

Division

Chemical Technology

Division 
Argonne National Laboratory, with facilities in the states of Illinois and Idaho, is owned by the United States Government and operated by The University of Chicago under the provisions of a contract with the Department of Energy.

\section{DISCLAIMER}

This report was prepared as an account of work sponsored by an agency of the United States Government. Neither the United States Government nor any agency thereof, nor The University of Chicago, nor any of their employees or officers, makes any warranty, express or implied, or assumes any legal liability or responsibility for the accuracy, completeness, or usefulness of any information, apparatus, product, or process disclosed, or represents that its use would not infringe privately owned rights. Reference herein to any specific commercial product, process, or service by trade name, trademark, manufacturer, or otherwise, does not necessarily constitute or imply its endorsement, recommendation, or favoring by the United States Government or any agency thereof. The views and opinions of document authors expressed herein do not necessarily state or reflect those of the United States Government or any agency thereof, Argonne National Laboratory, or The University of Chicago.

Available electronically at http://www.doe.gov/bridge

Available for a processing fee to U.S. Department of Energy and its contractors, in paper, from:

U.S. Department of Energy

Office of Scientific and Technical Information

P.O. Box 62

Oak Ridge, TN 37831-0062

phone: (865) 576-8401

fax: (865) 576-5728

email: reports@adonis.osti.gov 
ANL-02/22

Argonne National Laboratory

9700 South Cass Avenue

Argonne, IL 60439

\title{
SIMULANT FLOWSHEET TEST WITH MODIFIED SOLVENT FOR CESIUM REMOVAL USING CAUSTIC-SIDE SOLVENT EXTRACTION
}

\author{
by \\ Ralph A. Leonard, Scott B. Aase, Hassan A. Arafat, Cliff Conner, John R. Falkenberg, \\ Monica C. Regalbuto, and George F. Vandegrift
}

Chemical Technology Division

April 22, 2002 


\section{CONTENTS}

$\underline{\text { Page }}$

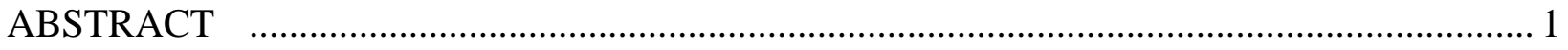

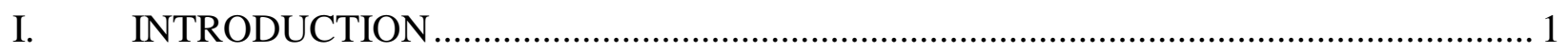

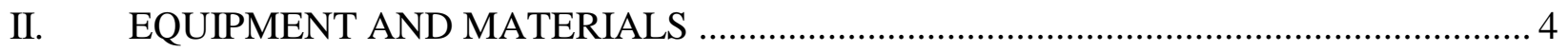

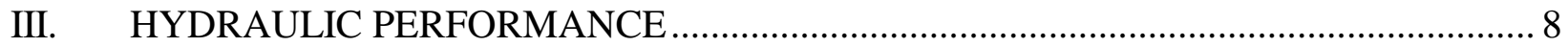

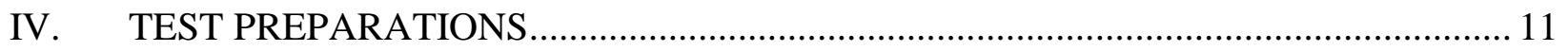

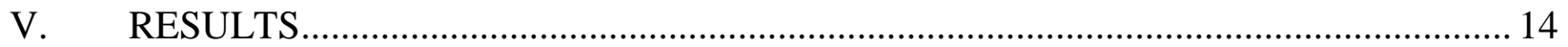

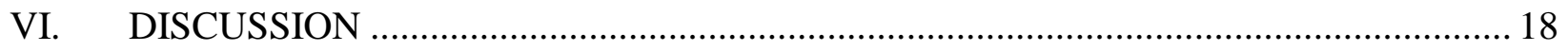

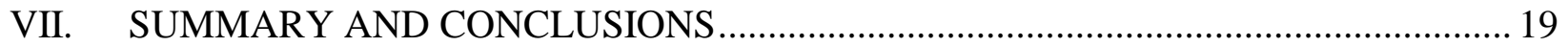

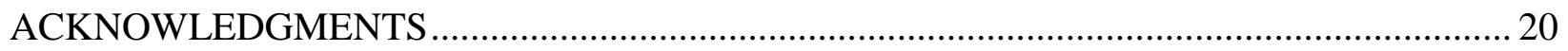

APPENDIX A. ADDITIONAL INFORMATION ON HYDRAULIC PERFORMANCE...... 21

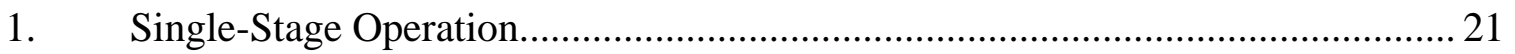

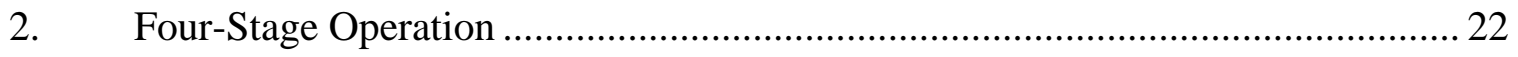

APPENDIX B. ADDITIONAL INFORMATION ON TEST PREPARATIONS ................. 24

1. Contactor Block Temperature Measured by Two Different Methods.................. 24

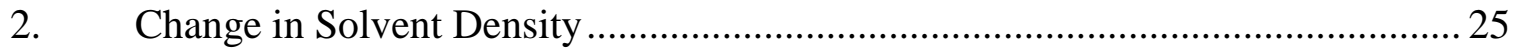

APPENDIX C. ADDITIONAL RESULTS ................................................................... 27

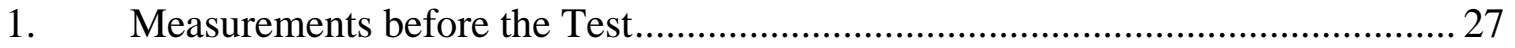

2. Measurements and Observations during the Test......................................... 28

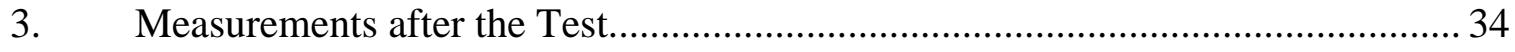

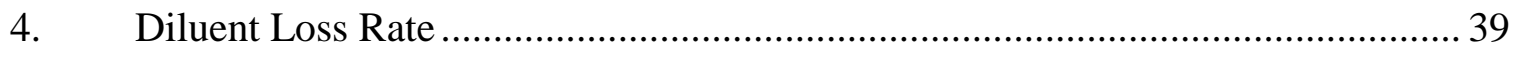

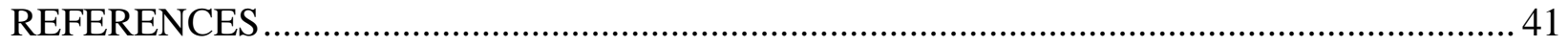




\section{FIGURES}

No.

$\underline{\text { Title }}$

$\underline{\text { Page }}$

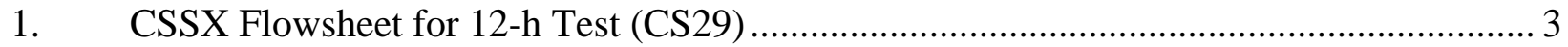

2. Schematic of Operating Contactor Stage …......................................................... 5

3. Cartridge Filter for SRS Simulant (DF) Feed …..................................................... 7

4. Thermocouple Wires on Body of 2-cm Contactor .................................................. 12

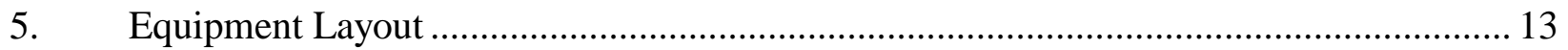

6. Changes in Decontamination Factor vs. Time for Test CS29 .................................... 15

7. Changes in Concentration Factor vs. Time for Test CS29.......................................... 16

8. Changes in Stripping Factor vs. Time for Test CS29.......................................... 17

B-1. Effect of Block Temperature on Temperature Difference between Two Methods .......... 25

C-1. Average Block and Effluent Temperatures during Test CS29 ................................. 33

C-2. Average Liquid Levels during Test CS29 ......................................................... 34

C-3. Cs Concentration Profile at End of Test CS29 ......................................................... 39

\section{TABLES}

No. $\quad \underline{\text { Title }} \quad \underline{\text { Page }}$

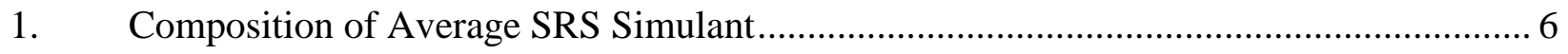

A-1. Hydraulic Performance of Single-Stage, 2-cm Contactor Using the Modified CSSX Solvent with Various Aqueous Phases ......................................................................... 22

A-2. Hydraulic Performance of Four-Stage, 2-cm Contactor Using the Modified CSSX Solvent with Various Aqueous Phases .......................................................................................... 23

B-1. Contactor Block Temperature Measured by Two Different Methods............................ 25

B-2. Change in CSSX Solvent Density with Time in 2-cm Centrifugal Contactor ................. 26

C-1. $\quad \mathrm{D}_{\mathrm{Cs}}$ Values from Batch-Equilibrium Measurements before Test CS29 ....................... 28 


\section{TABLES (continued)}

No.

$\underline{\text { Title }}$

$\underline{\text { Page }}$

C-2. Aqueous (DW) Raffinate for Test CS29

C-3. Aqueous Strip (EW) Effluent for Test CS29 ................................................... 30

C-4. Solvent Wash (FW) Effluent for Test CS29 ............................................................ 31

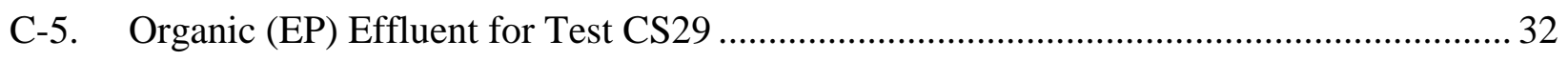

C-6. Effluent Concentrations during Test CS29 …...................................................... 35

C-7. Overall Material Balance for Cs during Test CS29 ............................................... 36

C-8. Cs Concentration in Equilibrated Stage Samples from Test CS29 .............................. 37 


\title{
SIMULANT FLOWSHEET TEST WITH MODIFIED SOLVENT FOR CESIUM REMOVAL USING CAUSTIC-SIDE SOLVENT EXTRACTION
}

\author{
by
Ralph A. Leonard, Scott B. Aase, Hassan A. Arafat, Cliff Conner, John R. Falkenberg, Monica C. Regalbuto, and George F. Vandegrift

\begin{abstract}
A modified solvent has been developed at Oak Ridge National laboratory (ORNL) for a caustic-side solvent extraction (CSSX) process that removes cesium (Cs) from Savannah River Site (SRS) tank waste. The modified solvent was evaluated using the same CSSX flowsheet, SRS simulant, and 33-stage minicontactor (2-cm centrifugal contactor) that had been used to test the previous CSSX solvent. As with the previous solvent, the key process goals were achieved: (1) the Cs was removed from the waste with decontamination factors greater than 40,000 and (2) the recovered Cs was concentrated by a factor of 15 in dilute nitric acid. Thus, the modified CSSX solvent can be used in place of the previous solvent while maintaining satisfactory hydraulic performance and still achieving process requirements at the bench scale.
\end{abstract}

\section{INTRODUCTION}

Savannah River Site (SRS) has 34 million gallons of high-level waste in 48 tanks that need to be decontaminated [LEVENSON-2000]. As a part of this process, cesium (Cs) will be removed from waste containing both supernatant liquid and dissolved salt cake, then vitrified for disposal. After the Cs is removed, the decontaminated solution will be immobilized in low-level grout.

To address the problem of removing Cs from alkaline solutions such as DOE tank wastes at Savannah River, South Caroline, and Hanford, Washington, a new extractant was developed at Oak Ridge National Laboratory (ORNL) that is very specific for Cs [BONNESEN-1998]. The new extractant is a calixarene-crown ether, calix[4]arene-bis(tert-octylbenzo-crown-6), designated BOBCalixC6. BOBCalixC6 is one component in a four-component solvent. The other three components are (1) a modifier, 1-(2,2,3,3-tetrafluoropropoxy)-3-(4-secbutylphenoxy)-2-propanol, also called Cs-7SB, which is an alkyl aryl polyether that keeps the extractant dissolved in the solvent and increases the ability to extract Cs in the extraction section; 
(2) a suppressant, trioctylamine (TOA), which suppresses effects from anionic organic impurities so that the Cs can be back-extracted from the solvent in the strip section; and (3) a diluent, Isopar ${ }^{\circledR} \mathrm{L}$, which is a mixture of branched hydrocarbons. In earlier tests of the CSSX flowsheet to prove the concept [LEONARD-2000, -2001A] and to demonstrate multiday operation [LEONARD-2001B, -2002], the solvent composition was 0.01 $\underline{\mathrm{M}} \mathrm{BOBCalixC6,0.50} \underline{\mathrm{M}} \mathrm{Cs}-7 \mathrm{SB}$, and $0.001 \underline{\mathrm{M}}$ TOA in Isopar L. For the flowsheet test discussed in this report, a modified CSSX solvent was used. It is referred to hereafter as the "CSSX solvent." Its composition is $0.007 \underline{\mathrm{M}}$ BOBCalixC6, $0.75 \underline{\mathrm{M}} \mathrm{Cs}-7 \mathrm{SB}$, and $0.003 \underline{\mathrm{M}}$ TOA in Isopar L [KLATT-2002]. With this change in composition, the CSSX solvent is no longer supersaturated with respect to BOBCalixC6. The modified solvent also has added resistance to third-phase formation at lower plant operating temperatures and to organic impurities that could limit back-extraction of the Cs from the solvent. The solvent density at $25^{\circ} \mathrm{C}$ is increased from 823 to $852 \mathrm{~g} / \mathrm{L}$. The $\mathrm{Cs}$ distribution ratios are changed only slightly.

The purpose of the test reported here was to demonstrate the CSSX process using the modified solvent. In this test, $30 \mathrm{~L}$ of SRS simulant was to be processed in $12.0 \mathrm{~h}$ as the modified solvent was recycled 9.8 times. As with the earlier solvent, the modified solvent was evaluated by seeing if it achieved both key CSSX process goals: (1) removing Cs from the waste with decontamination factors greater than 40,000 and (2) concentrating Cs by a factor of 15 in dilute nitric acid. The flowsheet for the 12-h test, given in Figure 1, shows the nominal flow rates for the test. Except for the solvent, this flowsheet is the same as that for the multiday test [LEONARD-2002]. In this test, designated "CS29," $1.15 \mathrm{~L}$ of CSSX solvent was used to process $36.3 \mathrm{~L}$ of SRS simulant in $13.8 \mathrm{~h}$ as the solvent was recycled 11.2 times.

This work is part of the integrated research and development program supporting the SRS High-Level Waste Salt Processing Project (SPP). The research and development program is managed by the Pacific Northwest National Laboratory, Tanks Focus Area. This work was performed in collaboration with the Savannah River Technology Center (SRTC), ORNL, and the Idaho National Engineering and Environmental Laboratory (INEEL). At the time the work reported here was being performed, SRTC personnel were preparing for a CSSX flowsheet test with actual waste in the 2 -cm centrifugal contactor using the modified solvent. Meanwhile, personnel at ORNL were working on solvent development and commercialization, and INEEL personnel were evaluating the hydraulics of the modified solvent in a larger $(5.5-\mathrm{cm})$ single-stage contactor. The 12-h test at Argonne National Laboratory (ANL) is a key part of this solvent extraction effort, as it is the first demonstration of the operability of the full CSSX process with the modified solvent. 
In the overall SPP work, the CSSX process was compared with two alternatives that also remove Cs from tank waste. These processes were (1) small-tank tetraphenylborate precipitation (STTP), where tetraphenylborate is used to precipitate out the Cs in small tanks, and (2) crystalline silicotitanate nonelutable ion exchange (CST), where crystalline silicotitanate is used to remove the Cs in packed beds [LEVENSON-2000]. In July 2001, the CSSX process was chosen as the Cs removal step designed for treatment of SRS tank waste at the Salt Waste Processing Facility (SWPF). For further information, see the Savannah River Site Salt Processing Alternatives Final Supplemental Environmental Impact Statement, DOE/EIS-0082S2D, which was released to the public on July 20, 2001. The official selection of CSSX as the Record of Decision was in October 2001; see the Federal Register, Vol. 66, No. 201, pp. 5275252756, October 17, 2001.

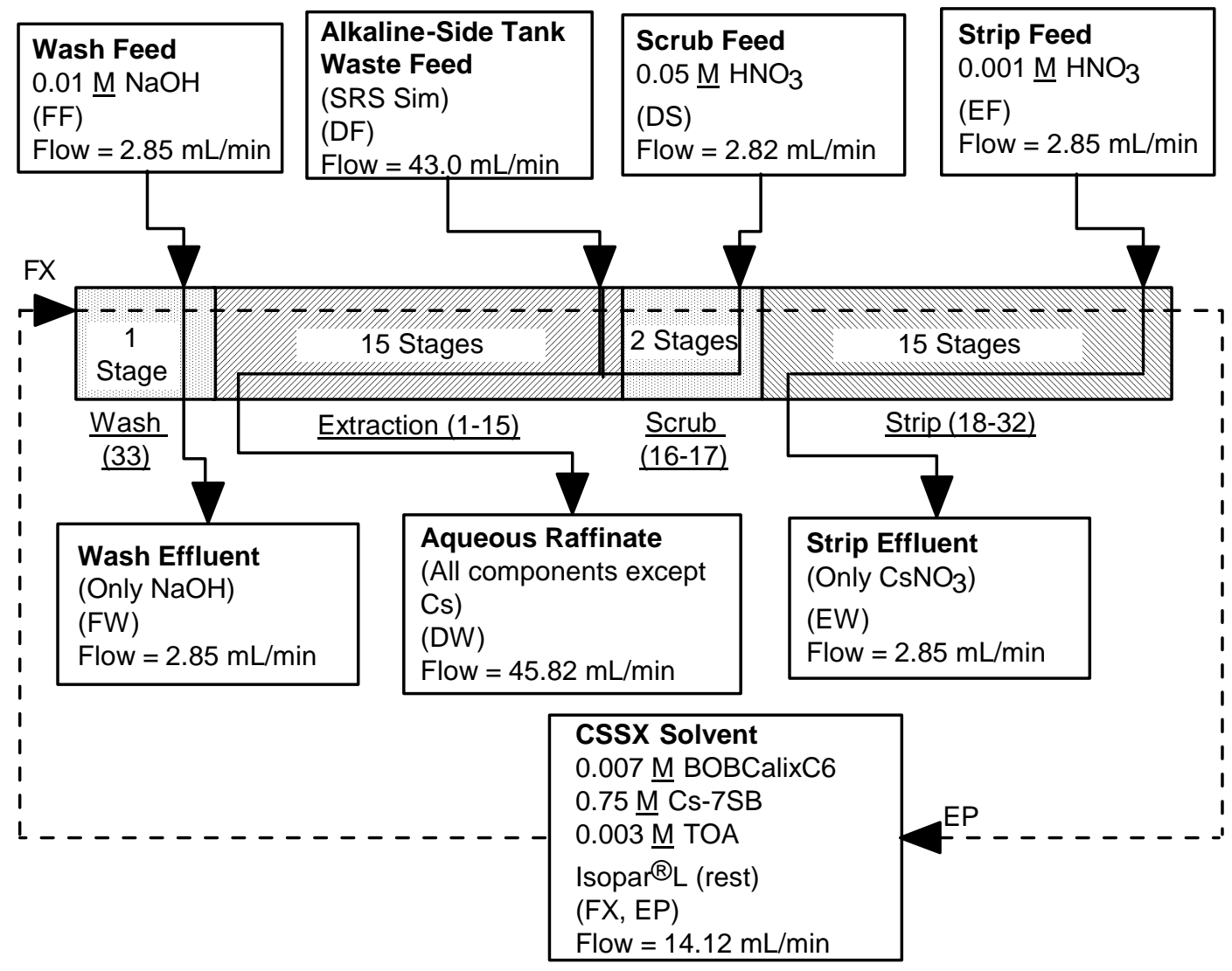

Fig. 1. CSSX Flowsheet for 12-h Test (CS29) 


\section{EQUIPMENT AND MATERIALS}

This solvent extraction test was performed in a 33-stage, 2-cm annular centrifugal contactor located in an ANL glovebox. A schematic of an operating contactor stage is given in Figure 2. The contactor, which is manufactured in banks of four stages, was built at ANL (see ANL print number CMT-E1265, entitled "2-cm Contactor" and dated 1/6/94). These contactor stages were modified in FY2000 to improve stage efficiency to $88 \pm 4 \%$ [LEONARD-2001A] and in FY2001 to improve hydraulics [LEONARD-2002]. Because the distribution ratio for Cs is very sensitive to temperature, increasing with decreasing temperature, the stages in the extraction section must be kept between 20 and $32^{\circ} \mathrm{C}$. For purposes of plant design, the upper temperature limit in the extraction section has been set at $25^{\circ} \mathrm{C}$, a conservative value that will make the CSSX process even more robust. If the stages in the extraction section get too hot, they will no longer be able to maintain the desired decontamination factor. If they get too cold, a second organic phase could form. A water-cooled chiller bar was used to control the temperature of the extraction section [LEONARD-2002]. The water, which was at $7.5^{\circ} \mathrm{C}$, was recirculated from a cooling bath located outside the glovebox. The temperature inside the glovebox during the test was $23 \pm 1^{\circ} \mathrm{C}$. Using the chiller bar, the block temperatures in the extraction section reached $28 \pm 2^{\circ} \mathrm{C}$ during the test while the temperatures of aqueous raffinate (effluent) were $26 \pm 2^{\circ} \mathrm{C}$. Since higher temperatures improve stripping, no chiller bar was attached to the strip section. The block temperatures there reached $41 \pm 2^{\circ} \mathrm{C}$ during the test while the temperatures of the strip effluents were $31 \pm 2^{\circ} \mathrm{C}$. No chiller bar was attached to either the scrub or wash sections, as the temperature in these two sections is not so important. 


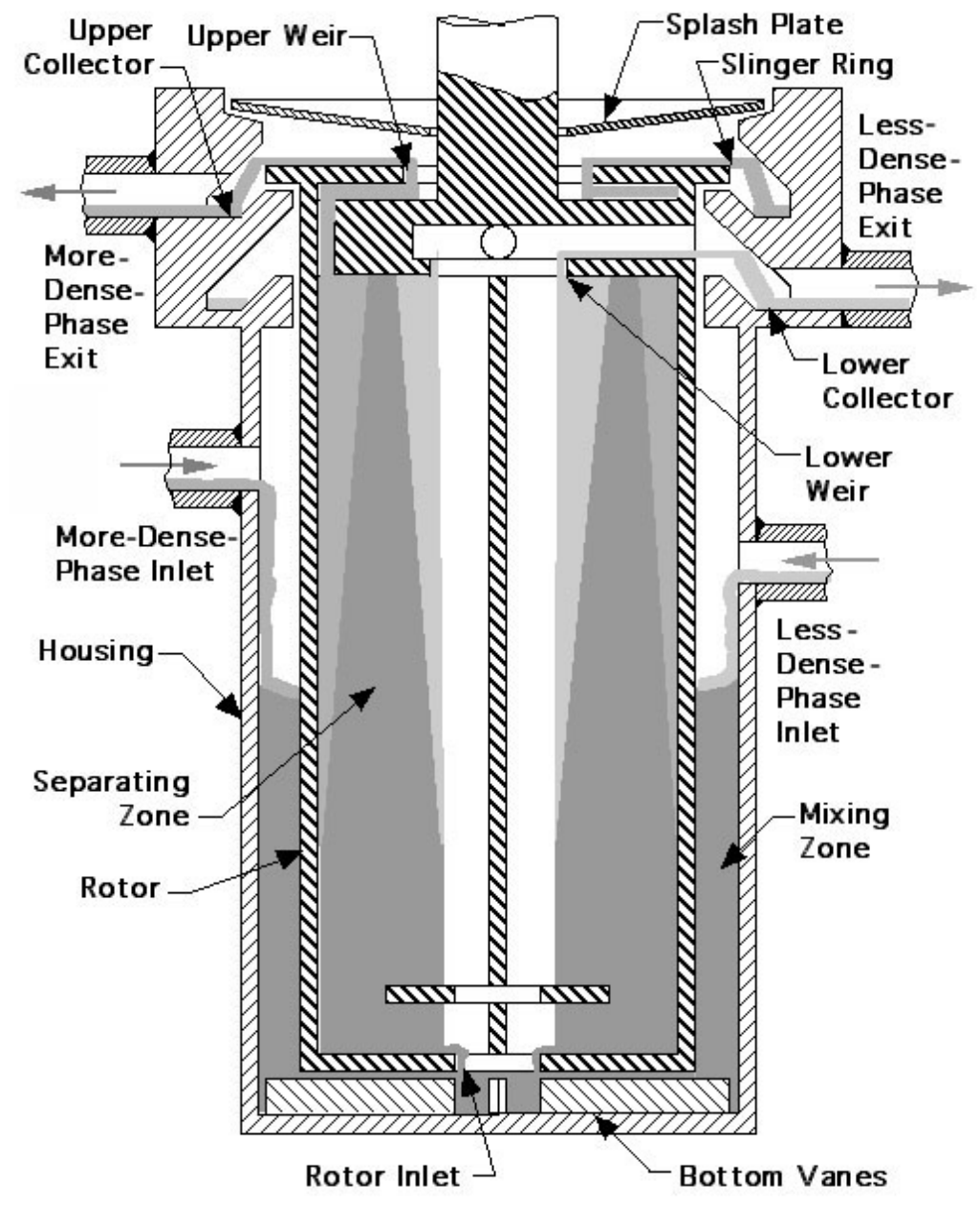

Fig. 2. Schematic of Operating Contactor Stage

For the 12-h CSSX flowsheet test, a highly alkaline simulant for tank supernate waste was prepared using a method supplied by SRS personnel [PETERSON-2000]. It has the composition given in Table 1 and is designated the "SRS simulant." Based on its composition, its estimated density is $1258 \mathrm{~g} / \mathrm{L}$ at $22^{\circ} \mathrm{C}$ [WALKER-1998]. Its measured density was $1249.6 \pm 1.4 \mathrm{~g} / \mathrm{L}$ at $17.5^{\circ} \mathrm{C}$. Assuming the effect of temperature on the density of the SRS simulant is the same as that for water, which is $-0.21 \mathrm{~g} / \mathrm{L}$ between 18 and $22^{\circ} \mathrm{C}$, the density of the simulant would be $1248.7 \mathrm{~g} / \mathrm{L}$ at $22^{\circ} \mathrm{C}$. When the $30 \mathrm{~L}$ of SRS simulant were blended with the $8 \mathrm{~L}$ of leftover simulant from the multiday test [LEONARD-2002], the density of the blend was $1237.3 \pm 0.9 \mathrm{~g} / \mathrm{L}$ at $18.2^{\circ} \mathrm{C}$. The continuing formation of solids in the leftover simulant apparently lowered the density of the filtered solution. When the density of the leftover simulant was measured a year earlier, just before the multiday test, it was $1250.8 \pm 2.6 \mathrm{~g} / \mathrm{L}$ at $22 \pm 3^{\circ} \mathrm{C}$. The density of this simulant was not measured again. Before the 12-h test, the SRS simulant was spiked with $1.0 \mathrm{mCi} / \mathrm{L}$ of ${ }^{137} \mathrm{Cs}$. Because of concerns about being able to measure a decontamination factor of 40,000 , the ${ }^{137} \mathrm{Cs}$ spike was twice as concentrated as that used in the 


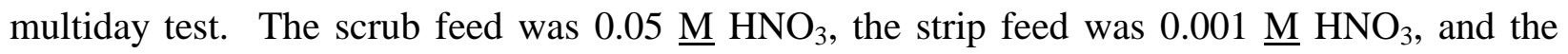
solvent wash feed was $0.01 \underline{\mathrm{M} \mathrm{NaOH}}$. All four aqueous feeds were prepared at ANL.

Table 1. Composition of Average SRS Simulant

\begin{tabular}{|c|c|c|c|}
\hline Component & Conc., mol/L & Component & Conc., mg/L \\
\hline $\mathrm{Na}^{+}$ & 5.6 & Copper & 1.44 \\
\hline $\mathrm{K}^{+}$ & 0.015 & Chromium & 75 \\
\hline $\mathrm{Cs}^{+}$ & $0.00014^{\mathrm{a}}$ & Ruthenium & 0.82 \\
\hline $\mathrm{OH}^{-}$ & 2.06 & Palladium & 0.41 \\
\hline $\mathrm{NO}_{3}{ }^{-}$ & 2.03 & Rhodium & 0.21 \\
\hline $\mathrm{NO}_{2}{ }^{-}$ & 0.50 & Iron & 1.44 \\
\hline $\mathrm{AlO}_{2}{ }^{-}$ & 0.28 & Zinc & 8 \\
\hline $\mathrm{CO}_{3}{ }^{2-}$ & 0.15 & Tin & 2.4 \\
\hline $\mathrm{SO}_{4}{ }^{2-}$ & 0.14 & Mercury & 0.05 \\
\hline $\mathrm{Cl}^{-}$ & 0.024 & Lead & 2.1 \\
\hline $\mathrm{F}^{-}$ & 0.028 & Silver & 0.01 \\
\hline $\mathrm{PO}_{4}{ }^{3-}$ & 0.007 & Tri-n-butyl phosphate (TBP) & 0.5 \\
\hline $\mathrm{C}_{2} \mathrm{O}_{4}{ }^{2-}$ & 0.008 & Di-n-butyl phosphate (DBP) & 25 \\
\hline $\mathrm{SiO}_{3}{ }^{2-}$ & 0.03 & Mono-n-butyl phosphate (MBP) & 25 \\
\hline $\mathrm{MoO}_{4}{ }^{2-}$ & 0.000078 & n-Butanol & 2 \\
\hline $\mathrm{NH}_{3}$ & 0.001 & Formate & 1500 \\
\hline & & Tri-methylamine (TMA) & 10 \\
\hline
\end{tabular}

${ }^{\mathrm{a}}$ This is the total Cs concentration in the average SRS tank waste. It is the Cs concentration used here with the addition of ${ }^{137} \mathrm{Cs}$ at a tracer level of $1.0 \mathrm{mCi} / \mathrm{L}$. The ${ }^{137} \mathrm{Cs}$ concentration in the average SRS tank waste is $22.6 \%$ of the total Cs concentration.

After the SRS simulant was prepared, it was filtered using a pleated cartridge filter made of polypropylene with a pore size of $0.45 \mu \mathrm{m}$. The cartridge filter, available from Cole-Parmer (Vernon Hills, Illinois; see catalog no. U-29830-10), is 10 in. $(25.4 \mathrm{~cm})$ long in a 304 stainless steel housing with a forged brass cap that is nickel plated. The filter has a throughput of 1 to 10 gpm (3.8 to $38 \mathrm{~L} / \mathrm{min})$, a filter area of $9.87 \mathrm{ft}^{2}\left(0.917 \mathrm{~m}^{2}\right)$, and a maximum pressure of $250 \mathrm{psi}$ (1.72 MPa). Because of the continuing formation of solid particles in the SRS simulant, it was filtered again just before being pumped to the contactor as the DF feed (see Fig. 1 for stage nomenclature). This cartridge filter was located inside the glovebox. The top of the filter can be seen in Figure 3, behind the two 4-L DF feed tanks. 


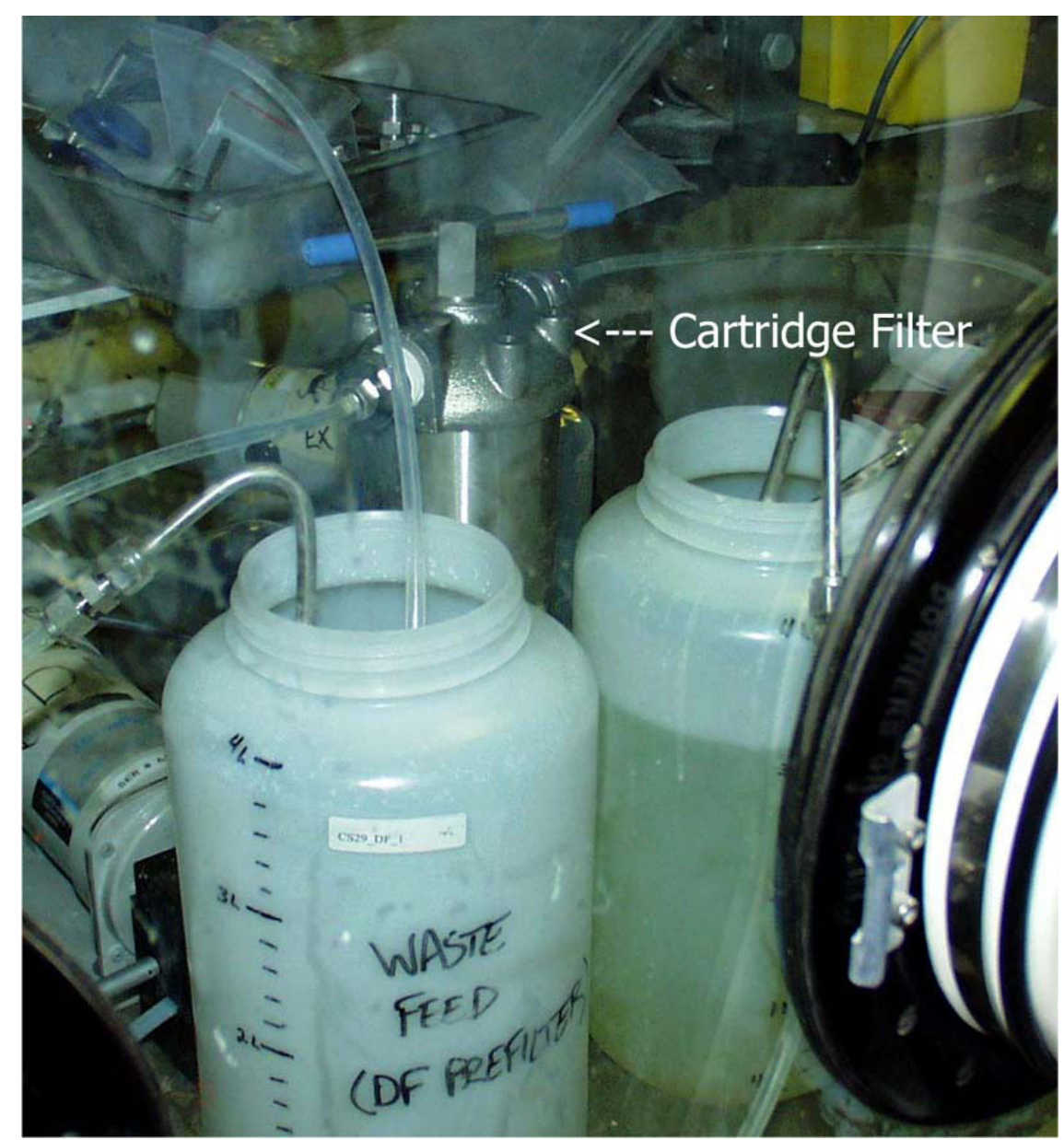

Fig. 3. Cartridge Filter for SRS Simulant (DF) Feed

A "four-component simulant" was used for hydraulic testing of the 2-cm contactor, operator training and the shakedown test (CS28), and the startup of the 12-h CSSX flowsheet test (CS29). This simulant approximates the composition of the SRS simulant. It is prepared by dissolving $127.48 \mathrm{~g}$ of $\mathrm{NaOH}$ first, then $105.04 \mathrm{~g}$ of $\mathrm{Al}\left(\mathrm{NO}_{3}\right)_{3} \bullet 9 \mathrm{H}_{2} \mathrm{O}, 34.5 \mathrm{~g}$ of $\mathrm{NaNO}_{2}$, and $99.85 \mathrm{~g}$ of $\mathrm{NaNO}_{3}$ in water for each liter of solution. As this simulant is prepared, $\mathrm{NaOH}$ reacts with $\mathrm{Al}\left(\mathrm{NO}_{3}\right)_{3}$ as follows:

$$
\mathrm{Al}\left(\mathrm{NO}_{3}\right)_{3}+4 \mathrm{NaOH} \rightarrow \mathrm{NaAlO}_{2}+3 \mathrm{NaNO}_{3}+2 \mathrm{H}_{2} \mathrm{O}
$$

Thus, the final ionic composition of the four-component simulant is $4.86 \underline{\mathrm{M} \mathrm{Na}}{ }^{+}, 2.07 \underline{\mathrm{M} \mathrm{OH}}$, $2.01 \underline{\mathrm{M} \mathrm{NO}_{3}}{ }^{-}, 0.5 \underline{\mathrm{M} \mathrm{NO}_{2}}{ }^{-}$, and $0.28 \underline{\mathrm{M}} \mathrm{AlO}_{2}{ }^{-}$. It has an estimated density of $1226 \mathrm{~g} / \mathrm{L}$ at $22^{\circ} \mathrm{C}$ [WALKER-1998]. Its measured density was $1215 \pm 2 \mathrm{~g} / \mathrm{L}$ at $22^{\circ} \mathrm{C}$.

The CSSX solvent for test CS29 was prepared by Peter Bonnesen at ORNL and shipped to ANL. The solvent density for this batch, $190 \mathrm{~W}$, was $851.6 \pm 1.7 \mathrm{~g} / \mathrm{L}$ at $25^{\circ} \mathrm{C}$ when measured 
at ORNL before shipping. It was $852.0 \pm 1.1 \mathrm{~g} / \mathrm{L}$ at $25^{\circ} \mathrm{C}$ when measured at $\mathrm{ANL}$ after receipt of the shipment. The earlier CSSX solvent for test CS28 was also prepared by Peter Bonnesen at ORNL and shipped to ANL. The solvent density for this batch, $150 \mathrm{~W}$, was $851.8 \pm 1.7 \mathrm{~g} / \mathrm{L}$ at $25^{\circ} \mathrm{C}$ when measured at ORNL before shipping. It was $840.6 \pm 0.9 \mathrm{~g} / \mathrm{L}$ at $25^{\circ} \mathrm{C}$ when measured at ANL after receipt of the shipment. When this solvent batch was examined closely, it was found to have stratified with a more-dense layer at the bottom of the solvent bottle. This layer was not a separate phase, but a more-dense region within the solvent. When the density was measured, the less-dense liquid above the more-dense region was taken as the density sample. Thus, the measured sample had a lower density than expected. When the solvent bottle was shaken, schlieren patterns could be seen as the more-dense liquid mixed with the rest of the solvent. After the initial mixing of the two regions, the schlieren patterns disappeared and did not reappear. The solvent density was re-measured and found to be $853.0 \pm 1.0 \mathrm{~g} / \mathrm{L}$ at $25^{\circ} \mathrm{C}$. This is in reasonable agreement with the original density measurements at ORNL. Based on a discussion with Peter Bonnesen of ORNL, it is possible that such a solvent separation could occur if the solvent had been cooled down to or below $0^{\circ} \mathrm{C}$. Shipping records showed that the 150W batch was shipped from ORNL by ground UPS on Friday, January 18, 2002, and arrived at ANL on Wednesday, January 23, 2002. The UPS truck was not heated. Weather records show that the solvent could have experienced temperatures as low as $12^{\circ} \mathrm{F}\left(-11^{\circ} \mathrm{C}\right)$. It is thought that these low temperatures, especially with some residual water in the solvent from the final solvent wash, allowed the partial separation of the solvent to occur. Mixing the partially separated solvent corrected the problem with no apparent harm to the solvent. The $\mathrm{D}_{\mathrm{Cs}}$ values for the solvent, which had been $10.1 \pm 1.1$ for the less-dense region, increased to $12.8 \pm 0.3$ after mixing. This increase put $\mathrm{D}_{\mathrm{Cs}}$ close to $14.1 \pm 0.3$, the value measured at ORNL before batch $150 \mathrm{~W}$ was shipped.

Recent work at ORNL has confirmed that CSSX solvent will stratify at low temperatures. When the two phases were warmed and remixed, solvent properties were restored [DELMAU2002].

\section{HYDRAULIC PERFORMANCE}

The hydraulic performance of a 33-stage, 2-cm centrifugal contactor was improved in FY2000 so that stage efficiency was increased during multistage operation. This increase was needed to carry out a full test of the CSSX flowsheet [LEONARD-2001A]. The most important change was smoothing the flow between stages. This smooth flow occurs naturally in larger contactors with interstage flows greater than 50 to $100 \mathrm{~mL} / \mathrm{min}$ [LEONARD-1999, -2001C]. 
This range of flow rates defines a transitional region between lower flow rates where liquid surface tension controls (releasing the liquid from the collector ring in discrete liquid slugs, which is called slug flow) and higher flow rates where liquid momentum controls (driving the liquid from the collector ring as a continuous stream). For smaller units with lower flow rates, the stage efficiency was increased from 60 to $90 \%$ by using a wire rope in each interstage line to smooth out the interstage flow and increase the liquid level in the annular mixing zone [LEONARD-2001A]. In subsequent testing of the CSSX flowsheet, a solvent wash stage was added so that there were 33 contactor stages.

The hydraulic performance of the 33-stage, 2-cm centrifugal contactor was further improved in FY2001 so that liquid levels in the interstage lines were reduced. If the levels get high enough, contactor flooding can occur. Flooding causes significant other-phase carryover and can shut down the contactor. These improvements were needed to ensure good contactor operation for the duration of a multiday test of the CSSX flowsheet. The improvements were obtained by (1) using a plastic insert to reduce the resistance to flow between the stages and (2) increasing the diameter of the upper rotor weir so that the maximum throughput for the extraction section is increased [LEONARD-2002]. As a general rule of thumb, a multistage contactor should be operated at no more than 50 to $67 \%$ of its maximum throughput for singlestage operation. When new contactors are built, the need for inserts can be eliminated by making the inlet lines tangential (or nearly tangential), rather than perpendicular, to the spinning rotor.

With these changes, the hydraulic performance of the 2-cm centrifugal contactor was very good for the CSSX flowsheet. However, it had to be checked with the modified solvent to be sure that nothing had changed. Of special concern was the higher density of the modified solvent. This could cause a problem when operating with aqueous phases having densities close to water, since the density of the two phases would be closer than before. When the densities are too close, the contactor rotor must be adjusted by reducing the diameter of the more-dense-phase (upper) weir so that it is closer to that of the less-dense-phase (lower) weir. However, the diameters of the upper weirs had just been enlarged to get better performance for the previous CSSX solvent. There was no easy way to make them smaller. If the diameter of the upper weir were too large, one would get significant $(>1 \%)$ organic phase in the aqueous effluent.

When the hydraulic performance of the 2 -cm centrifugal contactor was evaluated with the modified solvent and the various aqueous phases for the CSSX flowsheet, it was found to be very good. In the extraction section, the maximum throughput for single-stage operation was $105 \pm 15 \mathrm{~mL} / \mathrm{min}$. When this maximum throughput was exceeded, a carryover of $>1 \%$ aqueous phase in the organic effluent was observed. For four-stage operation, operation was okay at the 
planned operating conditions for the extraction section. This section has the highest throughput, with $45.8 \mathrm{~mL} / \mathrm{min}$ of aqueous phase and $14.12 \mathrm{~mL} / \mathrm{min}$ of organic phase, for a total flow rate of $60 \mathrm{~mL} / \mathrm{min}$.

As the solvent wash section is only one stage, the evaluation of hydraulic performance was only for one-stage operation. This was done by operating at a total flow rate of $40 \mathrm{~mL} / \mathrm{min}$ and an organic/aqueous (O/A) flow ratio of 5. Hydraulic performance was tested over the full range of flow conditions by making the unit pass through every O/A flow ratio as it approached a flow ratio of 5 . This was done by starting in both initially aqueous- and organic-continuous modes, as described in Appendix A. No problems were observed during these approaches to steady-state operation. The flow rate used was much higher than the $16.97 \mathrm{~mL} / \mathrm{min}$ required for the CSSX flowsheet.

The hydraulic performance in the scrub and strip sections was evaluated by testing the strip section. The maximum throughput for single-stage operation was $72 \pm 8 \mathrm{~mL} / \mathrm{min}$. When the maximum throughput was exceeded, a carryover of $>1 \%$ aqueous phase in the organic effluent $(>1 \% \mathrm{~A}$ in $\mathrm{O})$ was observed. Four-stage operation was generally okay at the planned operating conditions of $2.85 \mathrm{~mL} / \mathrm{min}$ of aqueous phase and $14.12 \mathrm{~mL} / \mathrm{min}$ of organic phase, for a total flow rate of $16.97 \mathrm{~mL} / \mathrm{min}$. In one case, starting initially in the aqueous-continuous mode, $>1 \% \mathrm{O}$ in $\mathrm{A}$ was seen in the aqueous effluent from stage 1. To correct this situation, the rotor at stage 1 was turned off for two minutes while the aqueous and organic flows were continued. The organic phase backed up in the organic interstage line between stages 1 and 2 . When the rotor was turned back on, the amount of organic phase in the aqueous effluent had become undetectable. Earlier, turning off the rotor for 0.5 and $1 \mathrm{~min}$ did not clear the organic phase in the aqueous effluent. In a second case, starting initially in the organic-continuous mode, $>1 \% \mathrm{O}$ in A was seen in the aqueous effluent from stage 1. To correct this situation, all pumps and rotors were turned off for $0.5 \mathrm{~min}$. When everything was restarted, the amount of organic phase in the aqueous effluent had become undetectable. If $0.5 \mathrm{~min}$ had not worked, longer times $(1,2$, or $5 \mathrm{~min}$ ) would have been used. This rest time gives the dispersion in the mixing zone a chance to coalesce. Subsequent attempts to recreate $>1 \%$ organic phase in the aqueous effluent were not successful.

While doing the 4-stage hydraulic performance tests under the strip-section conditions, a liquid level of 50 to $60 \%$ was observed in one of the interstage lines on the organic side, the line going from stage 1 to stage 2. Inspection of stage 2 showed that the insert for the organic inlet did not extend into the mixing zone. When the insert was adjusted so that it extended $0.8 \mathrm{~mm}$ into the mixing zone, the liquid level in the interstage line dropped to 10-20\%. This adjustment 
demonstrates how inserts reduce the flow resistance for the interstage liquid entering the mixing zone.

Further details on the hydraulic performance of the 2-cm contactor prior to the 12 -h test are given in Appendix A.

\section{TEST PREPARATIONS}

Preparations for the 12-h test (CS29) were similar to those used for the multiday test [LEONARD-2002]. Work was done on the contactor housings, rotor bodies, and feed tanks, and included training personnel and an operational readiness review. The contactor housings and the rotor bodies were cleaned before the test. As the motor/rotor assemblies were mounted, they were tested to be sure that rotor speed and direction of rotation were correct, the rotor runout was within specifications, and rotor rotation was not hindered by the contactor housing, the wire rope, or the insert. In the multiday test, digital thermometers were used to measure stage temperatures. They were attached to the center of the large stainless steel block that forms the top part of the contactor housing containing the collector rings and the upper mixing zone. In test CS29, they were replaced with thermocouples that can be seen in Figure 4. All of the thermocouples were connected to a single readout device that could be set manually to access any thermocouple. To simplify installation, the readout device was put in the glovebox. 


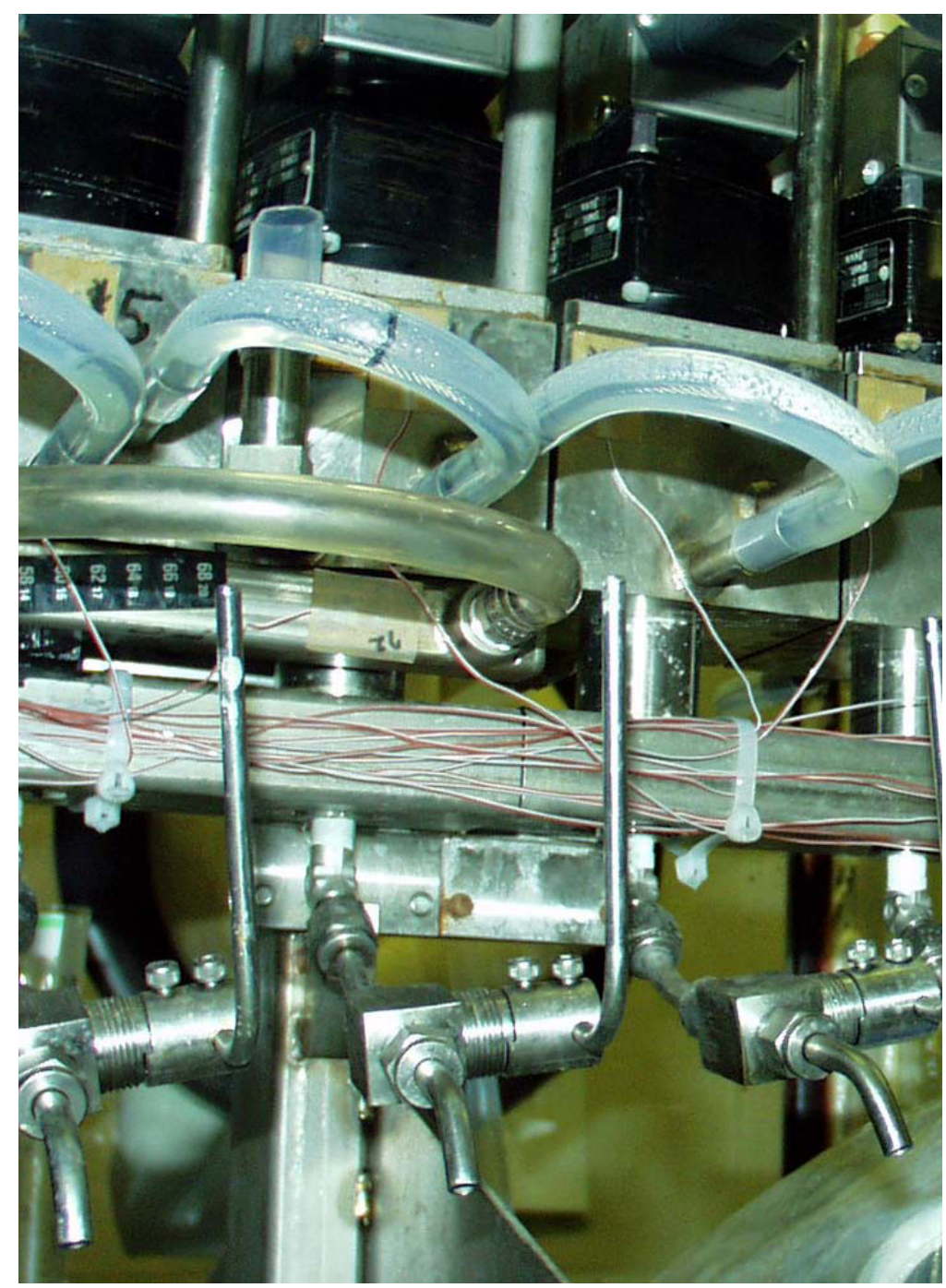

Fig. 4. Thermocouple Wires on Body of 2-cm Contactor

The DF feed tank was $50 \mathrm{~L}$, which was much smaller than the 207-L drum used for the multiday test. The smaller tank was used because test CS29 only needed to run for $12 \mathrm{~h}$. As shown in Figure 5, the tank was located in a limited access area outside the glovebox to minimize radiation exposure to personnel during the test. The hot DF feed was pumped to a 4-L pre-filter feed tank inside the glovebox. A second pump pushed the DF feed through the DF cartridge filter to the 4-L DF feed tank. A third pump transferred the DF feed to the contactor at stage 15 at the desired flow rate. During startup, a cold (nonradioactive) four-component simulant was used as the DF feed. It did not use the hot DF feed line into the glovebox. Instead, the cold simulant was bagged into the glovebox in 4-L bottles and was fed directly to stage 15 using only the third pump. Only one low-level waste (raffinate) drum was required. As shown in Figure 5, it was located in a limited access area outside the glovebox to minimize the number of bag-outs required during the test. All of the DW raffinate was pumped to this tank along with the FW 
effluent and the unused portion of the cold DF feed. The EW effluent was bagged out every 4 to $6 \mathrm{~h}$ to minimize radiation exposure to personnel during the test.

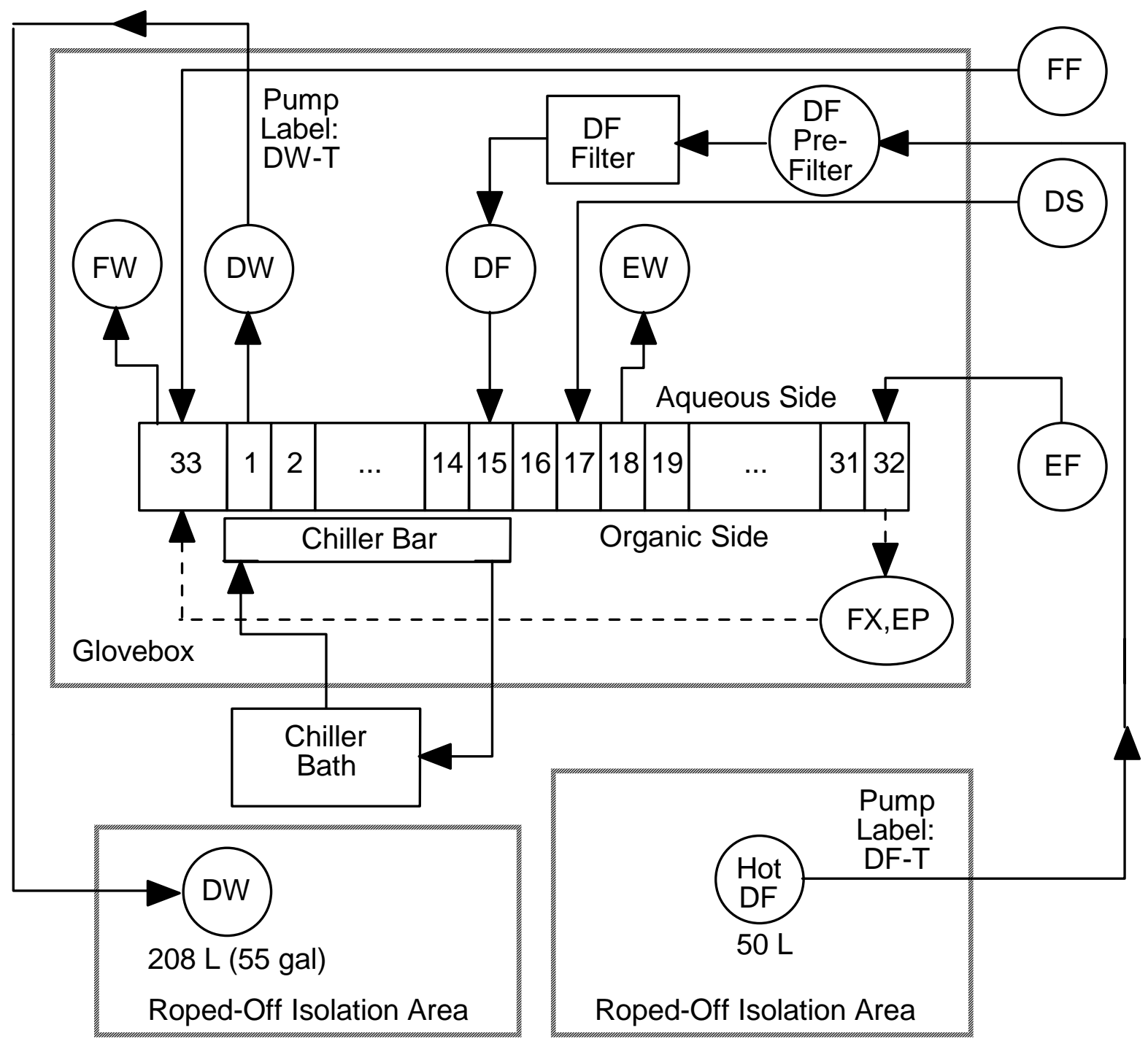

Fig. 5. Equipment Layout

Because the CSSX flowsheet was to be operated continuously for $12 \mathrm{~h}$, the test team was divided into two 12-h shifts. This division of people was done carefully so that each shift had all of the needed skills. On each shift, people were needed who (1) understood the overall process, (2) knew what data had to be taken, (3) understood the equipment, (4) could fix the equipment, and (5) could measure the Cs concentrations. In addition, the operators on both shifts received classroom and laboratory training. Classroom training gave every operator some knowledge in all of these areas. In the laboratory training, which was called test CS28, the contactor was operated by each shift using the nonradioactive four-component simulant as the DF feed. During 
this training, general readiness for the 12-h test was evaluated, including final checks of the equipment, the hydraulic performance of the contactor, the log sheets developed to record pertinent data and observations, the startup and shutdown procedures, and process operations designed to minimize individual and collective radiation doses. The laboratory training was very important and could not be replaced with more classroom training. While the two-shift operation worked well, three-shift operation is recommended for longer multiday tests.

For test CS28, the CSSX flowsheet was run cold, that is, with no radioactive Cs. The apparent ${ }^{137} \mathrm{Cs}$ concentration was measured in the various effluent streams. The results showed that ${ }^{137} \mathrm{Cs}$ measurements could not be made at the low concentrations required to detect a decontamination factor of 40,000. This problem occurred because the contactor test prior to test $\mathrm{CS} 28$ was a flowsheet test using $\mathrm{U}, \mathrm{Pu}, \mathrm{Np}$, and Tc. The residual contamination from these elements gave an alpha component in the liquid scintillation counting that precluded seeing ${ }^{137} \mathrm{Cs}$ at the low concentrations required. To get around this, the contactor was further cleaned with water until doing so no longer proved effective. This procedure was repeated with $1 \underline{\mathrm{M}} \mathrm{HNO}_{3}$. It

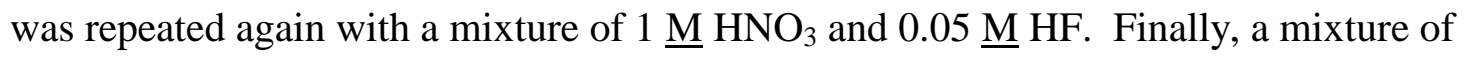

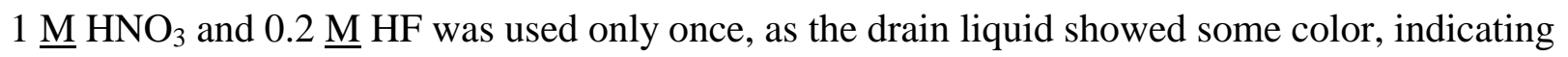
that the stainless steel of the contactor had been attacked by the HF. In the end, gamma counting was used in place of liquid scintillation counting. By increasing the ${ }^{137} \mathrm{Cs}$ in the DF feed from 0.5 to $1 \mathrm{mCi} / \mathrm{L}$, taking larger samples, and counting for long times, it was possible to detect ${ }^{137} \mathrm{Cs}$ at the low concentrations needed to measure a decontamination factor of 40,000.

Before test CS29 was started, our preparations were examined during an operational readiness review conducted by David Chamberlain of ANL on March 12, 2002. As a part of this review, the equipment and sample bottles were checked to see that they were properly labeled and corresponded with the procedure and log sheets. The safety review for the test and the radiation work permit were also reviewed along with the plans made to limit personnel radiation exposure.

Further details on test preparations prior to the 12-h test are given in Appendix B.

\section{RESULTS}

The CSSX process with the modified solvent was tested in a 33-stage, 2-cm centrifugal contactor using the flowsheet shown in Figure 1. This test was a nominal 12-h test that was carried out on March 19-20, 2002. The actual test time was $13.8 \mathrm{~h}$ (827 min). In the extraction 
section, the solvent extracts Cs from the aqueous SRS simulant as the two phases flow countercurrent to each other. As the solvent flows from stage 1 to 15 (see Fig. 1), its Cs concentration increases; as the SRS simulant flows in the opposite direction, from stage 15 to 1 , its Cs concentration decreases. The effectiveness of the extraction section is defined by the decontamination factor, which is the concentration of Cs in the aqueous SRS simulant (DF) entering stage 15 divided by that in the aqueous raffinate (DW) exiting stage 1 . As shown in Figure 6, the average decontamination factor for the test CS29, 420,000 $\pm 100,000$, exceeded the process goal of 40,000 by a factor of 10 . In calculating the average, the first point at 5 min into the test $(1.4 \mathrm{E}+06)$ was not included, as the process had not reached steady-state conditions. However, this point is shown in Figure 6.

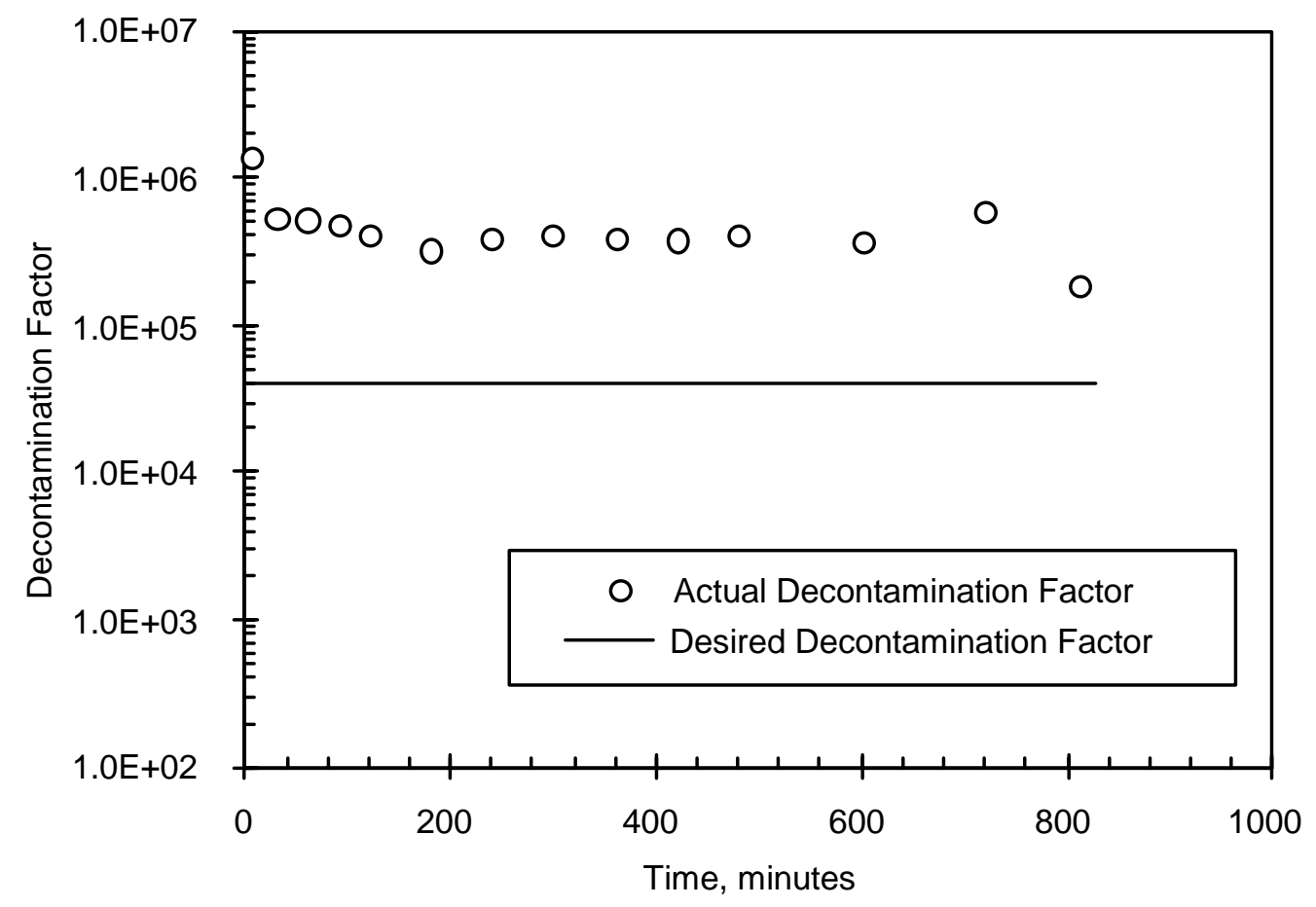

Fig. 6. Changes in Decontamination Factor vs. Time for Test CS29

The solvent leaving the extraction section at stage 15 is loaded with essentially all of the Cs that entered with the SRS simulant waste feed (DF). The solvent enters the scrub section, stages 16 and 17 in Figure 1, where weakly extracted impurities are removed along with any entrained aqueous phase. In addition, the entrained alkaline aqueous phase is neutralized and made slightly acidic. The scrubbed solvent then enters the strip section at stage 18. In the strip section, the Cs is recovered from the solvent and comes out in the aqueous strip effluent (EW). Since the flow of the aqueous strip feed (EF) is $1 / 15$ of the aqueous waste feed (DF) flow, and since essentially all of the Cs entering in the DF feed goes out in the aqueous strip effluent (EW), 
the $\mathrm{Cs}$ is concentrated by a factor of 15 in the EW effluent. This $[\mathrm{EW}] /[\mathrm{DF}]$ ratio, called the concentration factor, is plotted in Figure 7 as a function of time for test CS29. The average value of the concentration factor is $15.5 \pm 1.2$, which meets the second process goal. At 300 min into test CS29, the aqueous strip (EF) feed rate was determined to be high and was decreased by $7 \%$. Before this change, the average concentration factor was $14.7 \pm 0.3$; afterwards, it was $16.5 \pm 1.3$, an increase of $13 \%$. These results show how the concentration factor depends on the waste (DF) and strip (EF) feed rates and is controlled by them. In calculating the average concentration factor, the first point at 5 min into the test (8.6) was not included, as the process had not reached steady-state conditions. However, this point is shown in Figure 7.

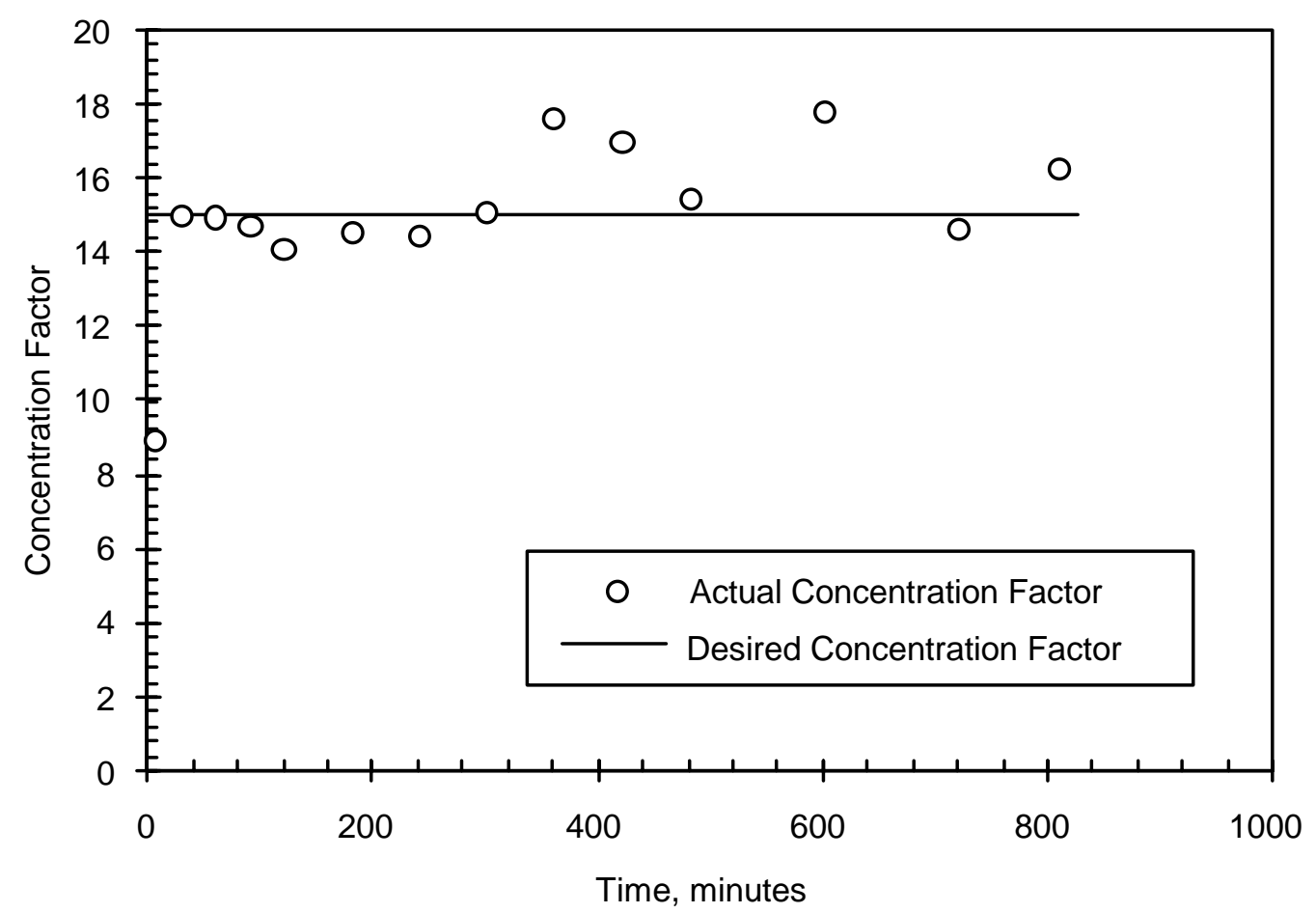

Fig. 7. Changes in Concentration Factor vs. Time for Test CS29

In the strip section, the solvent flows countercurrent to the aqueous strip solution of $0.001 \underline{\mathrm{M}} \mathrm{HNO}_{3}$. This solution strips the Cs from the solvent. That is, as the solvent flows from stage 18 to 32, its Cs concentration decreases; as the aqueous strip solution flows in the opposite direction, from stage 32 to 18 , its Cs concentration increases. The effectiveness of the strip section is defined by the stripping factor, which is the Cs concentration in the aqueous SRS simulant (DF) entering stage 15 divided by that in the organic effluent (EP) exiting stage 32 . As shown in Figure 8, the average stripping factor for test CS29, 400,000 $\pm 160,000$, exceeded the process goal of 40,000 by a factor of 10 . The required stripping factor is the same as the decontamination factor so that the solvent can be recycled. The stripping factors at 480 and 
600 min are not shown on the chart, as the EP concentrations were below the detection limit. However, the values for the average stripping factor were still high, >410,000 and >970,000, respectively.

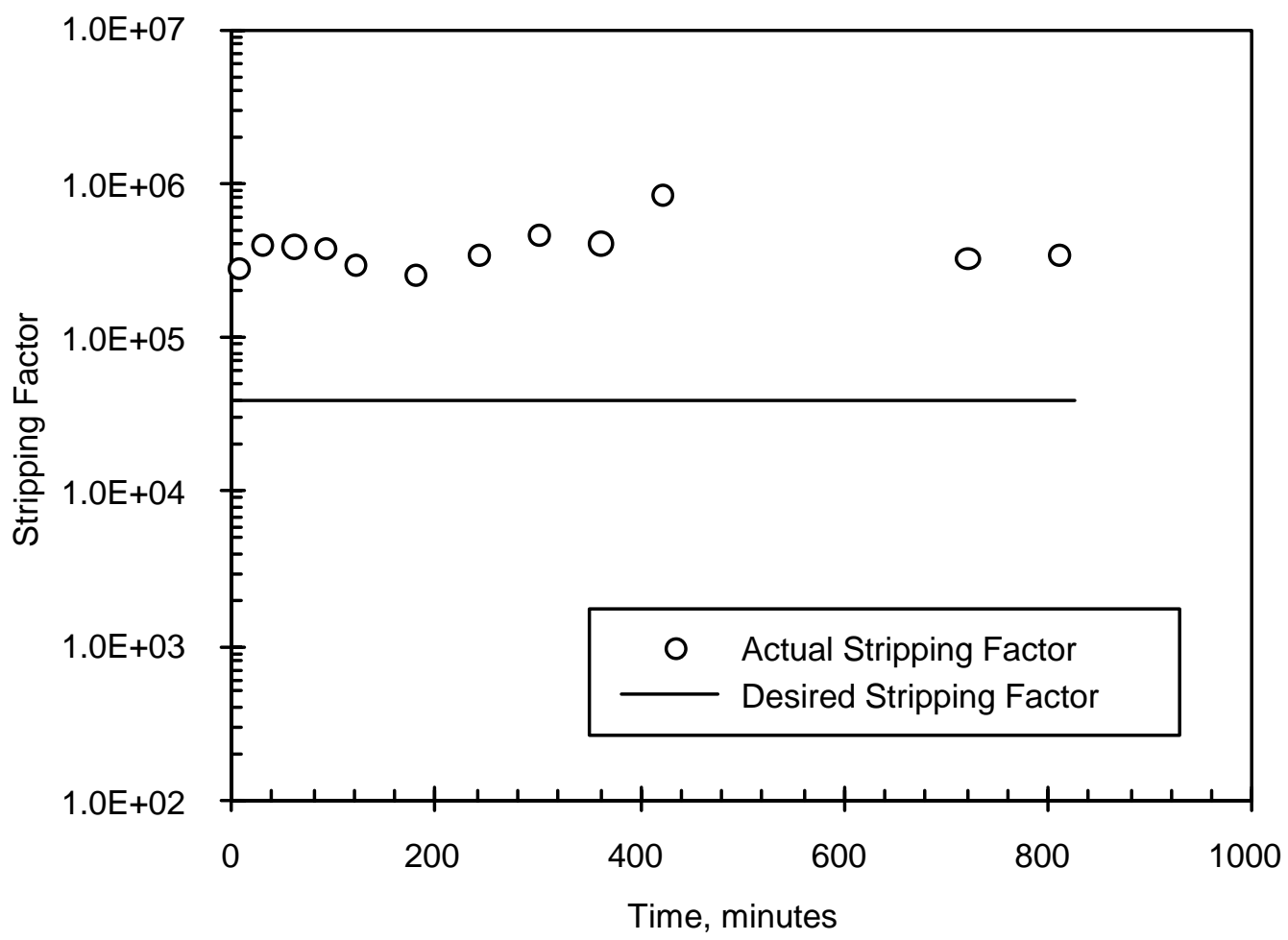

Fig. 8. Changes in Stripping Factor vs. Time for Test CS29

Thus, test CS29 met both process goals, that is, a decontamination factor >40,000 and a concentration factor of 15 were maintained while recycling the solvent 11 times over a test time of $13.8 \mathrm{~h}$. No evidence of degradation in solvent performance was observed, based on the relatively constant values for the decontamination and stripping factors over the $13.8 \mathrm{~h}$ of the test. There was evidence of diluent evaporation, because solvent density at $25^{\circ} \mathrm{C}$ increased from 852.0 to $856.2 \mathrm{~g} / \mathrm{L}$ over the $13.8 \mathrm{~h}$ of the test.

Additional results from the multiday test are given in Appendix C. This includes flow rates, temperatures, $\mathrm{pH}$ values, liquid levels in the interstage lines, Cs concentrations in the effluent streams, and Cs concentrations in both phases for each stage at the end of the test. The Cs concentration profile is compared with a computer model to determine stage efficiency. The calculations give an average stage efficiency of $85 \%$ for the extraction section and $92 \%$ for the strip section. These mass transfer efficiencies for multistage operation are similar to the 83 to $89 \%$ values seen during the multiday CSSX test [LEONARD-2002]. 


\section{DISCUSSION}

A major concern at the start of hydraulic testing was that the diameter of the upper weirs of the rotors was too large for the higher solvent density. If this were the case, there would have been significant $(>1 \%)$ organic phase in the aqueous effluent $(>1 \% \mathrm{O}$ in $\mathrm{A})$. This was not seen at all for the single-stage tests. During some multistage tests, $>1 \% \mathrm{O}$ in A was occasionally seen. However, this behavior seemed to be path-dependent. It could be eliminated very simply by shutting down all of the rotors and pumps, letting the dispersions in each stage break, and restarting the contactor. Thus, it does not appear that the diameter of the upper weirs of the rotors was too large for the higher density of the modified solvent. During this hydraulic testing, it was shown again how important the inserts are in keeping the liquid level in the interstage lines low during multistage operation. If the inlet ports in future contactors are made tangential to the spinning rotor, it should be possible to eliminate the inserts.

The approach of the CSSX process to steady state can be followed by looking at the data for the concentration factor. The rate at which this factor approaches steady state is controlled by the rate at which the DF feed brings Cs into the contactor. The concentration factor was 8.9 at $5 \mathrm{~min}(0.08 \mathrm{~h})$ into the test, 15.0 at $30 \mathrm{~min}(0.50 \mathrm{~h})$, and 15.0 at $60 \mathrm{~min}(1.00 \mathrm{~h})$. Thus, the CSSX process run in centrifugal contactors reaches steady state within $30 \mathrm{~min}(0.50 \mathrm{~h})$.

Solids had been a problem in the multiday test [LEONARD-2002]. To avoid this, the DF feed was filtered again just before it was used. When the rotor in stage 15 , the stage where any solids would enter, was inspected after the test, no white solids were seen on the inside wall of the rotor. Thus, with DF feed filtration immediately before processing, the solids problem seems to have been eliminated.

A simple density model was developed [LEONARD-2002] to predict the solvent density as a function of temperature and the concentrations of the extractant, modifier, suppressant, and diluent. The model assumes there is no interaction between solvent components that would affect their individual density contributions. In this model, BOBCalixC6 has a molecular weight of $1149.53 \mathrm{~g} / \mathrm{mol}$ and a density of $1054 \mathrm{~g} / \mathrm{L}$ at $25^{\circ} \mathrm{C}$; Cs-7SB has a molecular weight of $338.35 \mathrm{~g} / \mathrm{mol}$ and a density of $1173.5 \mathrm{~g} / \mathrm{L}$ at $25^{\circ} \mathrm{C}$; TOA has a molecular weight of $353.69 \mathrm{~g} / \mathrm{mol}$ and a density of $809 \mathrm{~g} / \mathrm{L}$ at $25^{\circ} \mathrm{C}$; and Isopar L has a density of $759.7 \mathrm{~g} / \mathrm{L}$ at $25^{\circ} \mathrm{C}$. Finally, the effect of temperature on density for all components is $-0.77(\mathrm{~g} / \mathrm{L}) /{ }^{\circ} \mathrm{C}$ in the neighborhood of $25^{\circ} \mathrm{C}$. With this model, the density of CSSX solvent at $25^{\circ} \mathrm{C}$ is calculated to be $851.5 \pm 2.0 \mathrm{~g} / \mathrm{L}$. This agrees very well with the measurements made at ANL and ORNL. This

model was used with the increase in solvent density to calculate the evaporative loss of diluent from the solvent. 
Calculations were made to see if the diluent loss rate from the solvent was consistent with the estimated diluent vapor pressure. The diluent loss rate was calculated in two different ways: (1) making a material (volume) balance for the solvent and (2) using the change in solvent density with the final solvent volume. The vapor pressure for Isopar $\mathrm{L}$ was estimated from data supplied by the manufacturer to be $31 \mathrm{~Pa}$ at $20^{\circ} \mathrm{C}$ and $124 \mathrm{~Pa}$ at $40^{\circ} \mathrm{C}$. The observed diluent losses could be explained for test CS29 by using these vapor pressures along with an estimate of the total gas flow through the $2-\mathrm{cm}$ contactor. The results suggest that, if the gas (air) flow through the contactor can be reduced, the diluent loss rate would be decreased. See Appendix C for details.

\section{SUMMARY AND CONCLUSIONS}

In preparation for the 12-h test, the hydraulic performance of the 2-cm contactor with the modified CSSX solvent was tested and found to be just as good as with the previous CSSX solvent. This good hydraulic performance was demonstrated for both single-stage and multistage operation.

During the training test, the contactor was found to have alpha contamination from the previous flowsheet test, which had used a lot of $\mathrm{U}, \mathrm{Pu}, \mathrm{Am}$, and $\mathrm{Np}$. There was enough alpha contamination to prevent measuring a Cs decontamination factor of 40,000 using liquid scintillation. Efforts to remove this material could not get the contamination down to a level at which liquid scintillation could be used. The contamination could get down to a level where gamma activity could be used if the amount of ${ }^{137} \mathrm{Cs}$ per unit volume were doubled, the sample volumes were increased, and the counting times were made longer. The concentration profile measured at the end of the test (see Fig. C-3 in Appendix C) shows that the Cs concentration changed more smoothly from stage to stage than was seen earlier in the multiday test [LEONARD-2002]. This is attributed to the additional cleaning that the contactor received.

Using the modified solvent, the CSSX process to remove Cs from SRS high-level waste was tested for $12 \mathrm{~h}$ in a 33-stage, 2-cm centrifugal contactor. This demonstration of the CSSX flowsheet used an average SRS simulant for the waste feed. The two key process goals were achieved and maintained: (1) the Cs was removed from the waste with decontamination factors greater than 40,000 and (2) the recovered Cs was concentrated by a factor of 15 in dilute nitric acid. In this test, $1.15 \mathrm{~L}$ of solvent was recycled a total of 11 times while processing $36 \mathrm{~L}$ of SRS simulant. The $\mathrm{Cs}$ had an average decontamination factor of 420,000 and an average concentration factor of 15.5 . The average stage efficiency was $85 \%$ for the extraction section and 
$92 \%$ for the strip section, which were very close to the mass transfer efficiencies seen in earlier CSSX tests [LEONARD-2001A].

This 12-h test demonstrated that the modified solvent works just as well with the CSSX flowsheet as the previous solvent, maintaining satisfactory hydraulic performance and achieving process requirements at the bench scale.

\section{ACKNOWLEDGMENTS}

This work was supported by the Office of Environmental Management of the U.S. Department of Energy through (1) the Office of Project Completion and (2) the Tank Focus Area

of the Office of Science and Technology under Contract W-31-109-Eng-38 with Argonne National Laboratory, managed by the University of Chicago.

The authors wish to acknowledge the help of Allen Bakel, Evan Freiberg, Kevin Quigley, Artem Guelis, Joe Hirsch, and Mark Sreniawski, all of the ANL Chemical Technology Division, in preparing for and carrying out the test. David Chamberlain of the ANL Chemical Technology Division conducted the operational readiness review. Peter Bonnesen of ORNL prepared the CSSX solvent used in this test. 


\section{APPENDIX A}

\section{ADDITIONAL INFORMATION ON HYDRAULIC PERFORMANCE}

Further information on the hydraulic performance of the 2-cm contactor is given here for the extraction, strip, and solvent wash sections of the CSSX flowsheet. Conditions in the scrub and strip sections were nearly identical, so the scrub section was not tested, as it was assumed that the scrub section will have the same hydraulic performance as the strip section. The solvent wash section was omitted in the multistage (four-stage) tests, since it has only one stage. To allow for the establishment of steady-state conditions, the flows were maintained for at least three residence times before samples were taken. For these tests, rotors X1 through X4 were placed in contactor housing stages 13A through 16A. These four 2-cm contactor rotors have been modified in the same way as the 2 -cm rotors in the glovebox. The rotor modifications are described in earlier reports [LEONARD-2001A, -2002].

In these hydraulic performance tests, contactor operation was defined as satisfactory if the other-phase carryover was $<1 \%$ in both effluent streams. To test the full range of contactor operation, the contactor was started in the initially aqueous-continuous mode and then in the initially organic-continuous mode. In a normal startup, the contactor is first filled with aqueous (more-dense) phase. Because of this, the operation is initially aqueous-continuous. To start up as an initially organic-continuous operation, the flow of the aqueous phase must be turned off while the organic (less-dense) phase continues to flow and the rotors continue to spin. By operating in this way for 3 to 6 residence times, the aqueous phase is purged from the mixing zones, making the dispersion there organic-continuous. When the aqueous flow is restarted, this gives contactor startup from an initially organic-continuous condition. By starting in both the initially aqueous- and organic-continuous modes, the full range of possible flow conditions is created in each stage and any path-dependent problems will be brought to light. If only one phase can be the continuous phase at a specific flow condition, the results will be about the same, no matter which phase was the initial continuous phase. By testing in this way and finding that the final hydraulic performance is satisfactory no matter which phase was the initial continuous phase, one can conclude that the section should be resistant to poor hydraulic performance triggered by process upsets.

\section{Single-Stage Operation}

To evaluate the hydraulic performance of the modified CSSX solvent in the various sections of the process, two-phase, single-stage tests were carried out in a 2-cm contactor. In these tests, the flow rate of each phase was increased while maintaining a constant O/A flow 
ratio. When hydraulic performance became unsatisfactory, the increases were stopped. At each flow rate, the hydraulic performance was evaluated by using aqueous-continuous and organiccontinuous initial modes. The amount of organic in the aqueous effluent $(O$ in $A)$ and the amount of aqueous in the organic effluent ( $\mathrm{A}$ in $\mathrm{O}$ ) were measured and the appearance of each effluent was noted. Test results are given in Table A-1 for the conditions in the extraction (fourcomponent simulant), strip (0.001 $\left.\underline{\mathrm{M}} \mathrm{HNO}_{3}\right)$, and solvent wash $(0.01 \underline{\mathrm{M}} \mathrm{NaOH})$ sections. They show that the modified solvent gives good hydraulic performance for single-stage operation over the range of conditions required for the CSSX flowsheet.

Table A-1. Hydraulic Performance of Single-Stage, 2-cm Contactor Using the Modified CSSX Solvent with Various Aqueous Phases

\begin{tabular}{|c|c|c|c|c|c|c|c|}
\hline Section & $\begin{array}{c}\text { O/A } \\
\text { Flow } \\
\text { Ratio }\end{array}$ & $\begin{array}{c}\text { Fotal } \\
\text { Rate, } \\
\text { mL/min }\end{array}$ & $\begin{array}{c}\text { Initial } \\
\text { Continuous } \\
\text { Phase }\end{array}$ & $\begin{array}{c}\text { O in A } \\
\text { Carryover, } \\
\%\end{array}$ & $\begin{array}{c}\text { A in O } \\
\text { Carryover, } \\
\%\end{array}$ & $\begin{array}{c}\text { Appearance } \\
\text { of A Phase }^{\text {a }}\end{array}$ & $\begin{array}{c}\text { Appearance } \\
\text { of O Phase }^{\text {a }}\end{array}$ \\
\hline Strip & 5 & 40 & A & $<0.5$ & $<0.3$ & Clr & Hazy \\
\hline$"$ & 5 & 40 & O & $<0.3$ & $<0.3$ & V cldy & Hazy \\
\hline$"$ & 5 & 40 & A & $<0.5$ & $<0.3$ & V cldy & V cldy \\
\hline$"$ & 5 & 40 & O & 0.5 & 0.3 & Cldy & V cldy \\
\hline$"$ & 5 & 63 & A & $<0.5$ & 0.8 & Cldy & V cldy \\
\hline$"$ & 5 & 63 & O & $<0.5$ & 0.8 & Cldy & V cldy \\
\hline$"$ & 5 & 80 & A & 0.5 & 3 & Clr & V cldy \\
\hline Solvent & 5 & 80 & O & 0.5 & 3 & Clr & V cldy \\
Wash & 5 & 40 & A & $<0.3$ & $<0.3$ & V clr & Cldy \\
\hline$"$ & 5 & 40 & O & $<0.5$ & $<0.3$ & Hazy & Hazy \\
\hline Extraction & 0.33 & 90 & A & $<0.3$ & $<0.3$ & Hazy & Crys clr \\
\hline$"$ & 0.33 & 90 & O & $<0.3$ & $<0.3$ & Hazy & Crys clr \\
\hline$"$ & 0.33 & 120 & A & $<0.3$ & 3 & Cldy & Clr \\
\hline$"$ & 0.33 & 120 & O & $<0.3$ & 3 & Cldy & Hazy \\
\hline
\end{tabular}

${ }^{\mathrm{a}}$ Appearance code: $\mathrm{cldy}=$ cloudy, $\mathrm{clr}=$ clear, crys $=$ crystal, hazy $=$ hazy, and $\mathrm{v}=$ very.

\section{Four-Stage Operation}

Tests were conducted in the 4-stage, 2 -cm contactor to evaluate multistage hydraulic performance of the modified CSSX solvent in the various sections of the process. The organic phase entered the contactor at stage 1 and exited at stage 4 . The aqueous phase entered the contactor at stage 4 and exited at stage 1. At each flow rate, the hydraulic performance was evaluated by using aqueous-continuous and organic-continuous initial modes. Test results are given in Table A-2 for the conditions in the extraction (four-component simulant) and strip 
$\left(0.001 \underline{\mathrm{M}} \mathrm{HNO}_{3}\right)$ sections. They show that the modified solvent gives good hydraulic performance for multistage operation over the range of conditions required for the CSSX flowsheet.

\section{Table A-2. Hydraulic Performance of Four-Stage, 2-cm Contactor Using the Modified CSSX Solvent with Various Aqueous Phases}

\begin{tabular}{|c|c|c|c|c|c|c|c|c|c|}
\hline Section & \begin{tabular}{|c|} 
O/A \\
Flow \\
Ratio \\
\end{tabular} & \begin{tabular}{|l} 
Total \\
Flow \\
Rate, \\
$\mathrm{mL} / \mathrm{min}$ \\
\end{tabular} & $\begin{array}{l}\text { Initial } \\
\text { Cont. } \\
\text { Phase }\end{array}$ & $\begin{array}{c}\text { Aqueous } \\
\text { Effluent: } \\
\text { Appearance } \\
\text { and O } \\
\text { Carryover } \\
(\mathrm{O} \text { in } \mathrm{A})^{\mathrm{a}} \\
\end{array}$ & \begin{tabular}{|c|} 
Organic \\
Effluent: \\
Appearance \\
and A \\
Carryover \\
$\left(\mathrm{A}\right.$ in O) ${ }^{\mathrm{a}}$ \\
\end{tabular} & $\begin{array}{c}\text { O-Side } \\
\text { Interstage Line } \\
\text { Backup } \\
\end{array}$ & $\begin{array}{c}\text { A-Side } \\
\text { Interstage Line } \\
\text { Backup }\end{array}$ & $\begin{array}{c}\text { Corrective } \\
\text { Action }\end{array}$ & $\begin{array}{c}\text { Post } \\
\text { Corrective } \\
\text { Action } \\
\text { Observations } \\
\end{array}$ \\
\hline Strip & 5 & 16.95 & A & $\begin{array}{c}\text { App. }=\mathrm{v} \\
\text { cldy } \\
\text { Carryover }= \\
4 \%\end{array}$ & $\begin{array}{c}\text { App. }=\text { hazy } \\
\text { Carryover }= \\
<0.3 \%\end{array}$ & $\begin{array}{l}\text { Line } 1-2,25 \% \\
\text { Line } 2-3,25 \% \\
\text { Line } 3-4,25 \%\end{array}$ & $\begin{array}{l}\text { Line } 4-3,10 \% \\
\text { Line } 3-2,10 \% \\
\text { Line } 2-1,10 \%\end{array}$ & $\begin{array}{l}\text { Switch the } \\
\text { rotor in } \\
\text { stage } 1 \text { for } \\
30 \mathrm{~s} \text {, then } \\
60 \mathrm{~s} \text {, then } \\
2 \mathrm{~min}\end{array}$ & $\begin{array}{l}\mathrm{O} \text { in } \mathrm{A} \text { is } 5 \% \\
\text { for } 30 \mathrm{~s}, 6 \% \\
\text { for } 60 \mathrm{~s} \text {, } \\
<0.3 \% \text { for } \\
2 \mathrm{~min}\end{array}$ \\
\hline Strip & 5 & 16.95 & $\mathrm{O}$ & $\begin{array}{c}\text { App. }=\mathrm{v} \\
\text { cldy } \\
\text { Carryover }= \\
1.1 \%\end{array}$ & $\begin{array}{c}\text { App. }=\text { hazy } \\
\text { Carryover = } \\
<0.3 \%\end{array}$ & $\begin{array}{l}\text { Line } 1-2,25 \% \\
\text { Line } 2-3,25 \% \\
\text { Line } 3-4,25 \%\end{array}$ & $\begin{array}{l}\text { Line } 4-3,10 \% \\
\text { Line } 3-2,10 \% \\
\text { Line } 2-1,10 \%\end{array}$ & $\begin{array}{c}\text { Turn all } \\
\text { rotors and } \\
\text { pumps off } \\
\text { simul- } \\
\text { taneously } \\
\text { for } 30 \mathrm{~s} \\
\end{array}$ & $\begin{array}{c}\text { Detectable O } \\
\text { in A } \\
\text { disappeared }\end{array}$ \\
\hline Strip & 5 & 16.95 & $\mathrm{O}$ & $\begin{array}{c}\text { App. }=\mathrm{v} \\
\text { cldy } \\
\text { Carryover }= \\
<0.3 \%\end{array}$ & $\begin{array}{c}\text { App. }=\text { hazy } \\
\text { Carryover = } \\
<0.3 \%\end{array}$ & $\begin{array}{l}\text { Line } 1-2,25 \% \\
\text { Line } 2-3,25 \% \\
\text { Line } 3-4,25 \%\end{array}$ & $\begin{array}{l}\text { Line } 4-3,10 \% \\
\text { Line } 3-2,10 \% \\
\text { Line } 2-1,10 \%\end{array}$ & None & $\begin{array}{c}\text { No problem } \\
\text { with O in A } \\
\text { for this repeat } \\
\text { test } \\
\end{array}$ \\
\hline Extr. & 0.33 & 60 & A & $\begin{array}{c}\text { App. }=\text { cldy } \\
\text { Carryover = } \\
<0.3 \%\end{array}$ & $\begin{array}{c}\text { App. }=\text { clr } \\
\text { Carryover }= \\
<0.3 \%\end{array}$ & $\begin{array}{l}\text { Line } 1-2,70 \% \\
\text { Line } 2-3,25 \% \\
\text { Line } 3-4,25 \%\end{array}$ & $\begin{array}{l}\text { Line } 4-3,20 \% \\
\text { Line } 3-2,20 \% \\
\text { Line } 2-1,20 \%\end{array}$ & None & $\begin{array}{c}\text { Not } \\
\text { applicable }\end{array}$ \\
\hline Extr. & 0.33 & 60 & $\mathrm{O}$ & $\begin{array}{c}\text { App. = cldy } \\
\text { Carryover = } \\
<0.3 \%\end{array}$ & \begin{tabular}{|c|} 
App. = crys \\
clr \\
Carryover $=$ \\
$<0.3 \%$
\end{tabular} & $\begin{array}{l}\text { Line } 1-2,50 \% \\
\text { Line } 2-3,25 \% \\
\text { Line } 3-4,25 \%\end{array}$ & $\begin{array}{l}\text { Line } 4-3,20 \% \\
\text { Line } 3-2,20 \% \\
\text { Line } 2-1,10 \%\end{array}$ & None & $\begin{array}{c}\text { Not } \\
\text { applicable }\end{array}$ \\
\hline
\end{tabular}

${ }^{\mathrm{a}}$ Appearance code: cldy $=$ cloudy, clr $=$ clear, crys $=$ crystal, hazy $=$ hazy, and $\mathrm{v}=$ very. 


\section{APPENDIX B}

\section{ADDITIONAL INFORMATION ON TEST PREPARATIONS}

Further information on test preparations for the 12-h test of the CSSX flowsheet (CS29) is given here. The additional information covers (1) the block temperature measured by two different methods and (2) the change in solvent density with use. These measurements were made in conjunction with the training test (CS28) for the 12-h test.

\section{Contactor Block Temperature Measured by Two Different Methods}

In the multiday CSSX flowsheet test (CS27), the temperature of the selected contactor housing blocks was measured using a digital thermometer taped to the middle of the upper block [LEONARD-2002]. This block is 3 in. (76.2 mm) wide by $3 \mathrm{in}$. (76.2 mm) deep and 2-9/16 in. $(65.1 \mathrm{~mm})$ high. The digital thermometer is a handheld model with a 3.5-in. $(88.9 \mathrm{~mm})$ probe (Fisher model $15-078 \mathrm{G}$ ) and an accuracy of $\pm 1^{\circ} \mathrm{C}$ traceable to NIST standards. For test CS29, the block temperature was measured by thermocouples taped to the upper right or left corner of the block, as shown in Figure 4. The thermocouples have an accuracy of $\pm 0.5^{\circ} \mathrm{C}$. To compare the two methods, the block temperatures of six contactor stages were measured by both methods during test CS28. The average temperatures, based on four readings over $3.5 \mathrm{~h}$, are given in Table B-1. During this test, the glovebox temperature was $22.2 \pm 0.3^{\circ} \mathrm{C}$. The data indicate that the difference between the two methods increases as the block temperature increases above room temperature. This difference between methods can be seen in Figure B-1. It is attributed to the larger size of the digital thermometer, which causes it to be influenced more by the glovebox temperature. A second reason for the difference between methods is that the thermocouple is mounted higher on the block, closer to the motor heating the block. The block temperature gives an indication of how much the contactor blocks are being heated by the motor and the amount of heat being removed by the chiller bar. The practical effect of this heating and cooling on the liquids flowing through the contactor is evaluated by measuring the effluent temperatures. 
Table B-1. Contactor Block Temperature Measured by Two Different Methods

\begin{tabular}{|c|c|c|c|c|}
\hline $\begin{array}{c}\text { Average } \\
\text { Thermocouple } \\
\text { Readings (lowest } \\
\text { first), }{ }^{\circ} \mathrm{C}\end{array}$ & $\begin{array}{c}\text { Average } \\
\text { Digital } \\
\text { Thermometer } \\
\text { Readings, }{ }^{\circ} \mathrm{C}\end{array}$ & $\begin{array}{c}\text { Thermocouple } \\
\text { Reading minus } \\
\text { Digital Thermometer } \\
\text { Reading, }{ }^{\circ} \mathrm{C}\end{array}$ & $\begin{array}{c}\text { Stage } \\
\text { Number }\end{array}$ & Stage Location \\
\hline $26.1 \pm 0.4$ & $26.5 \pm 0.3$ & $-0.4 \pm 0.6$ & 8 & Middle of extraction section \\
\hline $27.9 \pm 0.3$ & $27.0 \pm 0.2$ & $1.0 \pm 0.2$ & 15 & DF feed stage \\
\hline $28.7 \pm 0.7$ & $27.7 \pm 0.6$ & $1.0 \pm 0.6$ & 1 & DW raffinate stage \\
\hline $38.8 \pm 0.3$ & $37.2 \pm 0.3$ & $1.6 \pm 0.2$ & 18 & EW effluent stage \\
\hline $39.0 \pm 0.4$ & $37.5 \pm 0.4$ & $1.5 \pm 0.3$ & 32 & EP effluent stage \\
\hline $42.0 \pm 0.3$ & $38.7 \pm 0.4$ & $3.3 \pm 0.3$ & 25 & Middle of strip section \\
\hline
\end{tabular}

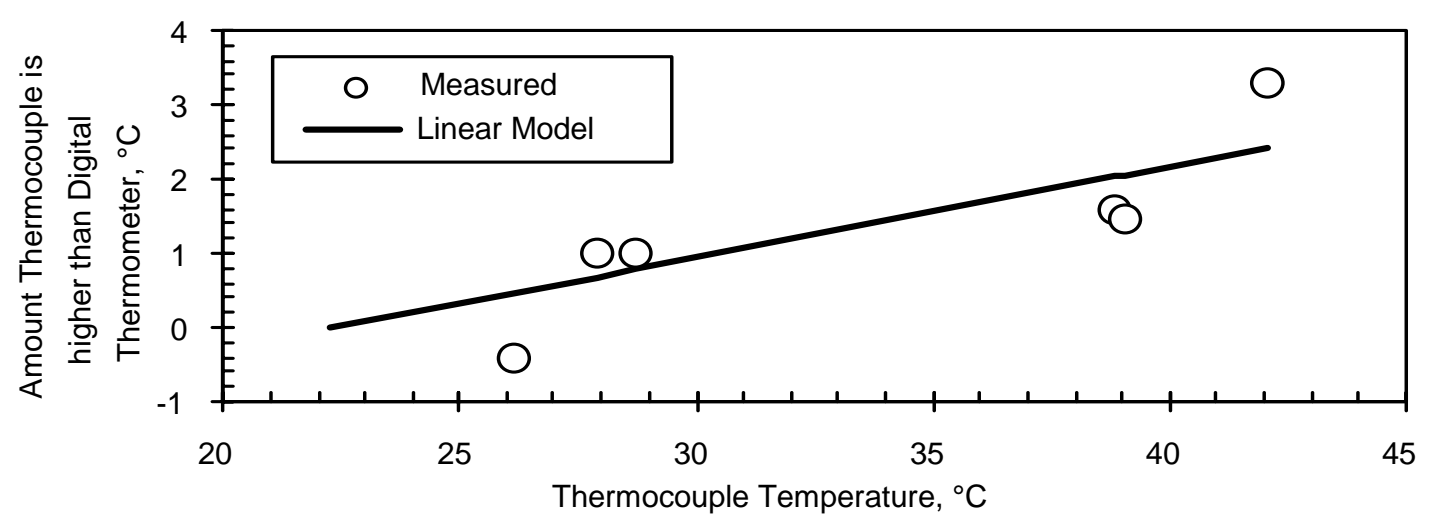

Fig. B-1. Effect of Block Temperature on Temperature Difference between Two Methods

\section{Change in Solvent Density}

The solvent density increased with time during the multiday test of the CSSX flowsheet [LEONARD-2002]. This increase is attributed to evaporative loss of diluent (Isopar L) as the solvent was recycled through the $2-\mathrm{cm}$ contactor. The smaller the solvent volume, the greater will be the effect of any diluent loss. We started with $1247 \mathrm{~mL}$ of solvent for test CS28. At the end of the test, there were $600 \mathrm{~mL}$ of solvent left in the EP/FX feed tank with some additional solvent in the contactor stages. The solvent density was measured at the start of test CS28 and $4 \mathrm{~h}$ later at the end of the test. The next day, the contactor was run another $3 \mathrm{~h}$ as part of a cleaning process to reduce alpha contamination. The density measurements, given in Table B-2, show that the density of the CSSX solvent slowly increased with time. 
Table B-2. Change in CSSX Solvent Density with Time in 2-cm Centrifugal Contactor

\begin{tabular}{|c|c|c|}
\hline $\begin{array}{c}\text { Total Time Solvent } \\
\text { Used, } \mathrm{h}\end{array}$ & $\begin{array}{c}\text { Solvent Density at } \\
25^{\circ} \mathrm{C}, \mathrm{g} / \mathrm{L}\end{array}$ & Notes \\
\hline 0 & $853 \pm 1$ & Fresh CSSX solvent at start of test CS28 \\
\hline 4 & $863 \pm 1$ & End of test CS28 \\
\hline 7 & $871 \pm 1$ & End of additional contactor operation \\
\hline
\end{tabular}

The amount of solvent lost by evaporation during test CS28 was determined by two methods. The first method used a material balance based on solvent volume. Of the $1247 \mathrm{~mL}$ of solvent that was present at the start of the test, $600 \mathrm{~mL}$ was left in the EP/FX tank; $464 \mathrm{~mL}$ was left in the contactor, based on the solvent flow rate $(14.5 \mathrm{~mL} / \mathrm{min})$ and the time it took for the solvent to pass through the 33 stages (32 $\mathrm{min}$ ); and 50 to $70 \mathrm{~mL}$ was in solvent samples (5 samples of 10 to $14 \mathrm{~mL}$ each). This leaves 113 to $133 \mathrm{~mL}$ of solvent that is not accounted for. This volume is assumed to be diluent that had evaporated. The second method used the change in solvent density in Table B-2 and the model for calculating solvent density given in LEONARD-2000. Based on the change in solvent density and an estimated $1064 \mathrm{~mL}$ of solvent left at the end of the test $(600 \mathrm{~mL}$ of solvent were in the EP/FX tank and $464 \mathrm{~mL}$ of solvent were estimated to be in the contactor and associated lines), the diluent loss was calculated to be 116 $\mathrm{mL}$. The two methods give the same diluent loss within the limits of experimental error. Based on the change in solvent density, the diluent loss rate was $0.48 \mathrm{~mL} / \mathrm{min}$. 


\begin{abstract}
APPENDIX C
ADDITIONAL RESULTS

Further results from the 12-h CSSX flowsheet test (CS29) are given here. These results include measurements made before and after the test, as well as measurements and observations made during the test. Finally, calculations were made to see if the change in solvent density could be explained by diluent evaporation from the solvent. These details supplement the test results given in the body of this report.

\section{Measurements before the Test}

Before the 12-h CSSX flowsheet test (CS29) was carried out, batch-equilibrium $\mathrm{D}_{\mathrm{Cs}}$ values were measured using the solutions and the volume ratios specified for the tests. The $\mathrm{D}_{\mathrm{Cs}}$ results, given in Table $\mathrm{C}-1$, agree fairly well with estimated $\mathrm{D}_{\mathrm{Cs}}$ values for the new CSSX solvent with only $0.001 \underline{\mathrm{M}}$ TOA (14.13 for the batch extraction; 1.32 and 1.35 for the two batch scrubs; and $0.104,0.062,0.049$, and 0.043 for the four batch strips) [KLATT-2002]. As that report also shows, $\mathrm{D}_{\mathrm{Cs}}$ in the extraction and scrub sections decreases as TOA increases to $0.003 \underline{\mathrm{M}}$. In the strip section, $\mathrm{D}_{\mathrm{Cs}}$ increases as TOA increases. The measured values in Table $\mathrm{C}-1$ show the same trends. Using the values in Table $\mathrm{C}-1$, the no-load $\mathrm{D}_{\mathrm{Cs}}$ values in the extraction and scrub sections and the $D_{C s}$ value at low Cs concentrations in the strip section were calculated as given in LEONARD-2001D. The results are given in the footnotes to Table C-1. Tests 1-4 were performed at the same time in the batch strip tests. When the $\mathrm{D}_{\mathrm{Cs}}$ value for test 4 was found to go up, test 5 was conducted. It showed that the $\mathrm{D}_{\mathrm{Cs}}$ value was continuing to go down. Our experience is that the consecutive batch strip values go down until they become constant. Thus, it is likely that there was some problem with the fourth strip test. For this reason, it is recommended that $\mathrm{D}_{\mathrm{Cs}}$ values for low $\mathrm{Cs}$ concentrations be based on the first three $\mathrm{D}_{\mathrm{Cs}}$ values for the strip section.
\end{abstract}




\section{Table C-1. $D_{\mathrm{Cs}}$ Values from Batch-Equilibrium Measurements before Test CS29}

\begin{tabular}{|c|c|c|c|c|}
\hline Section & $\begin{array}{c}\text { Batch Test } \\
\text { Number }\end{array}$ & $\begin{array}{c}\text { O/A Volume } \\
\text { Ratio }\end{array}$ & $\mathrm{D}_{\mathrm{Cs}}$ at $25^{\circ} \mathrm{C}$ & Notes \\
\hline Extraction & 1 & 0.31 & 11.95 & $\mathrm{a}$ \\
\hline Extraction & 2 & 0.31 & 11.59 & \\
\hline Scrub & 1 & 5.0 & 1.029 & $\mathrm{~b}$ \\
\hline Scrub & 2 & 5.0 & 1.239 & \\
\hline Strip & 1 & 5.0 & 0.106 & ${ }^{\mathrm{c}}$ \\
\hline Strip & 2 & 5.0 & 0.083 & \\
\hline Strip & 3 & 5.0 & 0.073 & \\
\hline Strip & 4 & 5.0 & 0.091 & \\
\hline Strip & 5 & 5.0 & 0.082 & \\
\hline
\end{tabular}

${ }^{a}$ Based on the extraction section data, the no load $D_{C s}$ value is $12.7 \pm 0.2$.

${ }^{b}$ Based on the scrub section data, the no load $\mathrm{D}_{\mathrm{Cs}}$ value is $1.22 \pm 0.15$.

${ }^{c}$ Based on the first three $\mathrm{D}_{\mathrm{Cs}}$ values for the strip section, the $\mathrm{D}_{\mathrm{Cs}}$ value at low $\mathrm{Cs}$ concentrations in the strip section is $0.053 \pm 0.010$; for all five values, $0.065 \pm 0.019$.

\section{Measurements and Observations during the Test}

During the flowsheet test CS29, effluent flow rates were measured by taking timed effluent samples. For flow rates above $10 \mathrm{~mL} / \mathrm{min}$, the collection time was $1 \mathrm{~min}$; for lower flow rates, it was $5 \mathrm{~min}$. In addition, the effluent appearance was checked, any other-phase carryover was noted, the effluent temperature was measured, and a sample of the liquid was taken for later determination of its $\mathrm{Cs}$ concentration. Using $\mathrm{pH}$ paper, the $\mathrm{pH}$ was measured for the aqueous effluent from the strip and solvent wash sections. The organic strip (EP) liquid effluent level in the EP/FX tank was noted. Time zero for the test was when hot (radioactive) DF feed was started. The test was continued until all of this SRS simulant was gone; the test ended at $827 \mathrm{~min}$.

Measurements and observations for the DW effluent are summarized in Table C-2. The overall DW flow rate was $43.0 \pm 1.2 \mathrm{~mL} / \mathrm{min}$, which was close to the target flow rate of $45.82 \mathrm{~mL} / \mathrm{min}$. The DW effluent was the coolest effluent, with an average temperature of $26.7 \pm 0.7^{\circ} \mathrm{C}$. This was expected, since the temperature in the extraction section is lowered by the water-cooled chiller bar. Before the test, the DF and DS flow rates were found to be $42.5 \mathrm{~mL} / \mathrm{min}$ (target $43.0 \mathrm{~mL} / \mathrm{min}$ ) and $2.86 \mathrm{~mL} / \mathrm{min}$ (target $2.82 \mathrm{~mL} / \mathrm{min}$ ), respectively. During the test, the DS flow rate was found to be $2.92 \pm 0.05 \mathrm{~mL} / \mathrm{min}$. Since the DF flow rate was not measured during the test, it was calculated from the DS and DW flow rates as $40.1 \pm 1.2 \mathrm{~mL} / \mathrm{min}$. 
Table C-2. Aqueous (DW) Raffinate for Test CS29

\begin{tabular}{|c|c|c|c|c|c|}
\hline $\begin{array}{c}\text { Sample } \\
\text { Number }\end{array}$ & Time, $\min$ & $\begin{array}{c}\text { DW Flow Rate, } \\
\mathrm{mL} / \mathrm{min}\end{array}$ & $\begin{array}{c}\text { DW Temp, } \\
{ }^{\circ} \mathrm{C}\end{array}$ & $\begin{array}{c}\text { DW Other-Phase } \\
\text { Carryover, } \%\end{array}$ & $\begin{array}{c}\text { DW } \\
\text { Appearance }^{\mathrm{a}}\end{array}$ \\
\hline 1 & 5 & 44.0 & 25.8 & $<0.5$ & Sl hazy, yel \\
\hline 2 & 30 & 44.0 & 26.0 & $<0.5$ & Sl hazy, yel \\
\hline 3 & 60 & 44.0 & 26.6 & $<0.5$ & Clr, yel \\
\hline 4 & 90 & 42.0 & 26.6 & $<0.5$ & Clr, yel \\
\hline 5 & 120 & 44.5 & 28.8 & $<0.5$ & Clr, yel \\
\hline 6 & 180 & 42.0 & 26.7 & $<0.5$ & Hazy, yel \\
\hline 7 & 240 & 42.5 & 26.8 & $<0.5$ & Clr, yel \\
\hline 8 & 300 & 43.0 & 26.6 & $<0.5$ & Clr, yel \\
\hline 9 & 360 & 43.0 & 26.5 & $<0.5$ & Clr, yel \\
\hline 10 & 420 & 40.0 & - & $<0.5$ & Clr, yel \\
\hline 11 & 480 & 44.0 & - & $<0.5$ & Clr, yel \\
\hline 12 & 600 & 44.0 & 26.3 & $<0.5$ & Clr, yel \\
\hline 13 & 720 & 43.0 & 26.7 & $<0.5$ & Clr, yel \\
\hline 14 & 810 & 42.0 & 26.8 & $<0.5$ & Sl hazy, yel \\
\hline
\end{tabular}

a Appearance code: clr $=$ clear, hazy $=$ hazy, $\mathrm{sl}=$ slight, and yel $=$ yellow.

Measurements and observations for the EW effluent are summarized in Table C-3. The overall EW flow rate was $2.86 \pm 0.42 \mathrm{~mL} / \mathrm{min}$, which was very close to the target flow rate of $2.85 \mathrm{~mL} / \mathrm{min}$. The EW effluent had an average temperature of $30.2 \pm 0.8^{\circ} \mathrm{C}$. The EW effluent was acidic throughout the test, with $\mathrm{pH}$ ranging from 3 to 5. Based on earlier tests of the $\mathrm{pH}$ paper, a pH of 3 corresponds to $0.003 \underline{\mathrm{M}} \mathrm{HNO}_{3}$ and a $\mathrm{pH}$ of 5, to $0.001 \underline{\mathrm{M}} \mathrm{HNO}_{3}$. Before the test, the $\mathrm{EF}$ flow rate was found to be $2.82 \mathrm{~mL} / \mathrm{min}$.

The EF flow rate could be measured and controlled fairly well manually using an electronic balance in conjunction with a FMI rotary piston pump. This technique, which is given in LEONARD-2001A, was also used for the other two cold feeds (DS and FF). During the first $300 \mathrm{~min}$ of test CS29, the EF flow rate was $3.13 \pm 0.01 \mathrm{~mL} / \mathrm{min}$. During this same time, the EW flow rate was $2.84 \pm 0.31 \mathrm{~mL} / \mathrm{min}$. This shows that flow rate variations are increased as the aqueous phase moves the 15 stages of the strip section. This is also seen as intermittent (slug) flow when the aqueous phase exits the strip section. Since slug flow in an effluent line will not affect stage efficiency, there are no wire ropes in the effluent lines. At 300 min into test CS29, the EF flow rate was lowered slightly so that it was closer to the target value. After $300 \mathrm{~min}$, the EF flow rate was $2.90 \pm 0.02 \mathrm{~mL} / \mathrm{min}$. During this same time, the EW flow rate was $2.85 \pm 0.54 \mathrm{~mL} / \mathrm{min}$. 
Table C-3. Aqueous Strip (EW) Effluent for Test CS29

\begin{tabular}{|c|c|c|c|c|c|c|}
\hline $\begin{array}{c}\text { Sample } \\
\text { Number }\end{array}$ & Time, $\mathrm{min}$ & $\begin{array}{c}\text { EW Flow Rate, } \\
\mathrm{mL} / \mathrm{min}\end{array}$ & $\begin{array}{c}\text { EW Temp, } \\
{ }^{\circ} \mathrm{C}\end{array}$ & $\begin{array}{c}\text { EW Other-Phase } \\
\text { Carryover, } \%\end{array}$ & $\begin{array}{c}\text { EW } \\
\text { Appearance }^{\mathrm{a}}\end{array}$ & $\mathrm{pH}$ \\
\hline 1 & 10 & 2.65 & 28.7 & $<1.0$ & Hazy & 4 \\
\hline 2 & 35 & 2.55 & 28.6 & $<1.0$ & Clr & 3.5 \\
\hline 3 & 65 & 2.80 & 30.2 & $<1.0$ & Hazy, col & 4 \\
\hline 4 & 95 & 2.70 & 28.9 & $<1.0$ & Hazy, col & 4 \\
\hline 5 & 125 & 3.50 & 30.6 & $<1.0$ & Clr & 4 \\
\hline 6 & 185 & 2.90 & 30.7 & $<1.0$ & Clr, col & - \\
\hline 7 & 245 & 2.80 & 30.7 & $<1.0$ & Clr, col & 4 \\
\hline 8 & 305 & 3.40 & 30.8 & $<1.0$ & Clr, col & 4 \\
\hline 9 & 365 & 2.50 & 30.5 & $<1.0$ & Clr, col & 4 \\
\hline 10 & 425 & 3.10 & 30.8 & $<1.0$ & Clr, col & 4 \\
\hline 11 & 485 & 2.50 & 30.6 & $<1.0$ & Clr, col & 4 \\
\hline 12 & 605 & 2.20 & 30.4 & $<1.0$ & Clr, col & 3 \\
\hline 13 & 725 & 3.70 & 30.4 & $<1.0$ & Clr, col & 3 \\
\hline 14 & 815 & 2.78 & 30.8 & $<1.0$ & Crys Clr & 3.5 \\
\hline
\end{tabular}

${ }^{a}$ Appearance code: $\mathrm{clr}=$ clear, $\mathrm{col}=$ colorless, crys $=$ crystal, and hazy $=$ hazy.

Measurements and observations for the FW effluent are summarized in Table C-4. The overall FW flow rate was $2.86 \pm 0.13 \mathrm{~mL} / \mathrm{min}$, which was very close to the target flow rate of $2.85 \mathrm{~mL} / \mathrm{min}$. The $\mathrm{FW}$ effluent had an average temperature of $27.0 \pm 0.4^{\circ} \mathrm{C}$ and was alkaline throughout the test, with $\mathrm{pH}$ ranging from 9 to 12 , based on measurements using $\mathrm{pH}$ paper. Before the test, the FF flow rate was found to be $2.86 \mathrm{~mL} / \mathrm{min}$. During the first $360 \mathrm{~min}$ of test $\mathrm{CS} 29$, the FF flow rate was $3.01 \pm 0.07 \mathrm{~mL} / \mathrm{min}$. During this same time, the FW flow rate was $2.83 \pm 0.16 \mathrm{~mL} / \mathrm{min}$. This shows that flow rate variations are increased only slightly, if at all, as the aqueous phase moves through the one stage of the solvent wash section. At 360 min into test CS29, the FF flow rate was lowered slightly so that it was closer to the target value. After $360 \mathrm{~min}$, the FF flow rate was $2.92 \pm 0.06 \mathrm{~mL} / \mathrm{min}$. During this same time, the FW flow rate was $2.90 \pm 0.07 \mathrm{~mL} / \mathrm{min}$. 
Table C-4. Solvent Wash (FW) Effluent for Test CS29

\begin{tabular}{|c|c|c|c|c|c|c|}
\hline $\begin{array}{c}\text { Sample } \\
\text { Number }\end{array}$ & Time, $\min$ & $\begin{array}{c}\text { FW Flow Rate, } \\
\mathrm{mL} / \mathrm{min}\end{array}$ & $\begin{array}{c}\text { FW Temp, } \\
{ }^{\circ} \mathrm{C}\end{array}$ & $\begin{array}{c}\text { FW Other-Phase } \\
\text { Carryover, } \%\end{array}$ & $\begin{array}{c}\text { FW } \\
\text { Appearance }^{\mathrm{a}}\end{array}$ & $\mathrm{pH}$ \\
\hline 1 & 10 & 2.70 & - & $<1.0$ & Crys clr, sl yel & 12 \\
\hline 2 & 35 & 2.80 & - & $<1.0$ & Sl hazy, v lt yel & 11 \\
\hline 3 & 65 & 2.84 & 27.0 & $<1.0$ & Clr, col & 10 \\
\hline 4 & 95 & 2.60 & 27.7 & $<1.0$ & Clr, col & 9 \\
\hline 5 & 125 & 2.70 & 27.3 & $<1.0$ & Clr & 8 \\
\hline 6 & 185 & 3.00 & 26.7 & $<1.0$ & Clr, col & 9 \\
\hline 7 & 245 & 3.00 & 26.8 & $<1.0$ & Clr, col & 9 \\
\hline 8 & 305 & 3.00 & 26.4 & $<1.0$ & Clr, col & 9 \\
\hline 9 & 365 & 2.90 & 26.8 & $<1.0$ & Clr, col & 9 \\
\hline 10 & 425 & - & - & $<1.0$ & Hazy, col & - \\
\hline 11 & 485 & 2.90 & - & $<1.0$ & Hazy, col & 10 \\
\hline 12 & 605 & 2.80 & 27.2 & $<1.0$ & Sl cldy, col & 9 \\
\hline 13 & 725 & 2.90 & - & $<1.0$ & Clr, col & 9 \\
\hline 14 & 815 & 3.00 & - & $<1.0$ & Cldy & 11 \\
\hline
\end{tabular}

${ }^{a}$ Appearance code: cldy $=$ cloudy, clr $=$ clear, col = colorless, crys $=$ crystal, hazy $=$ hazy, lt $=$ light, $\mathrm{sl}=$ slight, $\mathrm{v}=$ very, and yel $=$ yellow .

Measurements and observations for the EP effluent are summarized in Table C-5. The overall EP flow rate was $13.4 \pm 2.2 \mathrm{~mL} / \mathrm{min}$, which is close to the target flow rate of $14.12 \mathrm{~mL} / \mathrm{min}$. Before the test, the FX flow rate was found to be $14.25 \pm 0.25 \mathrm{~mL} / \mathrm{min}$. The EP effluent had an average temperature of $30.8 \pm 0.4^{\circ} \mathrm{C}$. In one case, $>1 \% \mathrm{~A}$ in $\mathrm{O}$ was seen in the EP effluent. On average, the amount of $\mathrm{A}$ in $\mathrm{O}$ was small, $0.3 \pm 0.5 \%$. The liquid level in the effluent/feed (EP/FX) tank dropped slowly throughout the test. This is a result of taking solvent samples and losing diluent from the solvent by evaporation. In addition, the level also reflects variations in the liquid holdup in the contactor with time. At the start of the test, the fresh solvent had a density of $852.0 \mathrm{~g} / \mathrm{L}$. At the end of the $13.8-\mathrm{h}(827-\mathrm{min})$ test, the solvent had a density of $856.2 \mathrm{~g} / \mathrm{L}$. This density increase is only $40 \%$ of that seen for the solvent in test CS28 (see Appendix B), which was shorter, only $4 \mathrm{~h}$. The solvent used in test CS28 was from batch 150W; that for test CS29 was from batch 190W. As mentioned in Section II, batch 150W became stratified during shipment from ORNL to ANL, while batch $190 \mathrm{~W}$ did not. This suggests that differences between these two batches allowed batch $150 \mathrm{~W}$ to lose diluent by evaporation more rapidly. However, there is no reason to expect that this would be the case. The difficulty in measuring diluent loss and the difference in test conditions provide a more likely explanation for the apparent difference in loss rates between the two solvent batches. 
Table C-5. Organic (EP) Effluent for Test CS29

\begin{tabular}{|c|c|c|c|c|c|c|}
\hline $\begin{array}{c}\text { Sample } \\
\text { Number }\end{array}$ & $\begin{array}{c}\text { Time, } \\
\text { min }\end{array}$ & $\begin{array}{c}\text { EP Flow Rate, } \\
\mathrm{mL} / \mathrm{min}\end{array}$ & $\begin{array}{c}\text { EP Temp, } \\
{ }^{\circ} \mathrm{C}\end{array}$ & $\begin{array}{c}\text { EP Other-Phase } \\
\text { Carryover, \% }\end{array}$ & $\begin{array}{c}\text { EP Appearance } \\
\text { EP }\end{array}$ & $\begin{array}{c}\text { EP/FX Tank } \\
\text { Level, mL }\end{array}$ \\
\hline 1 & 5 & 7.5 & 29.0 & $<0.005$ & Crys clr & 590 \\
\hline 2 & 30 & 12.5 & 30.6 & 0.3 & Crys clr & 585 \\
\hline 3 & 60 & 15.5 & 31.2 & 0.03 & Clr, col & 550 \\
\hline 4 & 90 & 18.0 & 31.4 & 0.08 & Clr, col & 550 \\
\hline 5 & 120 & 9.0 & 31.3 & 0.006 & - & 550 \\
\hline 6 & 180 & 14.0 & 30.9 & $<0.005$ & Clr, col & 525 \\
\hline 7 & 240 & 11.5 & 30.0 & $<0.005$ & Clr, col & 500 \\
\hline 8 & 300 & 15.0 & 30.7 & 1.8 & Clr, col & 500 \\
\hline 9 & 360 & 11.0 & 30.4 & 0.005 & Clr, col & 500 \\
\hline 10 & 420 & 14.0 & - & 0.2 & Clr, col & 500 \\
\hline 11 & 480 & 13.0 & - & 0.03 & Clr, col & 470 \\
\hline 12 & 600 & 12.5 & 30.9 & 0.3 & Clr, col & 475 \\
\hline 13 & 720 & 14.5 & - & 0.03 & Clr, col & 500 \\
\hline 14 & 810 & 13.5 & 31.0 & 0.8 & Crys clr & 430 \\
\hline
\end{tabular}

${ }^{\mathrm{a}}$ Appearance code: $\mathrm{clr}=$ clear, $\mathrm{col}=$ colorless, and crys $=$ crystal.

The amount of solvent lost by evaporation during test CS29 was determined by two methods. The first method used a material balance based on solvent volume. Of the $1150 \mathrm{~mL}$ of solvent estimated at the start of the test, $430 \mathrm{~mL}$ was left in the EP/FX tank; $482 \mathrm{~mL}$ was left in the contactor, based on the solvent flow rate $(13.38 \mathrm{~mL} / \mathrm{min})$ and the time it took for the solvent to pass through the 33 stages (36 min); and 140 to $196 \mathrm{~mL}$ consisted of solvent samples (14 samples of 10 to $14 \mathrm{~mL}$ each). This leaves 42 to $98 \mathrm{~mL}$ of solvent that is not accounted for. This volume is assumed to be diluent that evaporated. The second method used the change in solvent density and the model for calculating solvent density given in LEONARD-2000. Based on the change in solvent density and an estimated $912 \mathrm{~mL}$ of solvent at the end of the test, the diluent loss was calculated to be $42 \mathrm{~mL}$. Within the limits of experimental error, the two methods give the same diluent loss. Based on the change in solvent density, the diluent loss rate was $0.05 \mathrm{~mL} / \mathrm{min}$. This is only $10 \%$ of the diluent loss rate seen in test CS28. The higher diluent loss rate for test CS28 may indicate that (1) the contactor motors were running longer before startup, (2) the coolant flow to the chiller bar was not started until the cold DF feed was flowing into the extraction section, (3) the experimental error for this measurement is high, and, perhaps, (4) differences between the two solvent batches.

Other conditions measured during flowsheet test CS29 were the temperatures of selected contactor stages and the level of the liquid flowing through the interstage lines. The temperatures of the contactor stages were measured using thermocouples taped to the contactor block. The average temperature for each stage is given as a function of stage number in Figure C-1. All contactor temperatures were higher than the surrounding (glovebox) temperature of 
$22.9 \pm 0.4^{\circ} \mathrm{C}$. The stages cooled by the chiller bar, stages $1-15$, had the lowest block temperatures, ranging from 27.4 to $30.3^{\circ} \mathrm{C}$. The stages away from the chiller bar and with no external feeds, stages 20-30, had the highest block temperatures, ranging from 40.6 to $43.1^{\circ} \mathrm{C}$. In every stage where a comparison is possible, the effluent stream temperature is between the contactor block temperature for that stage and the room (glovebox) temperature.

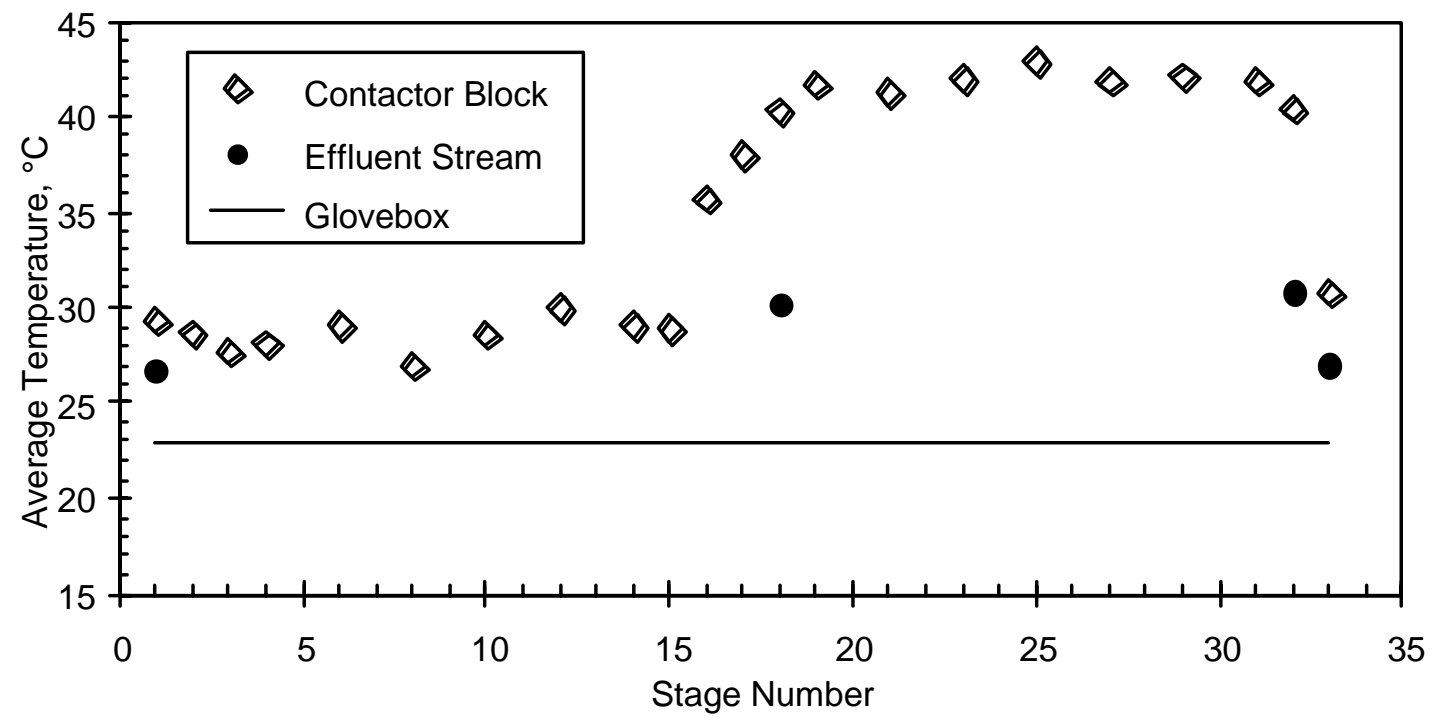

Fig. C-1. Average Block and Effluent Temperatures during Test CS29

The level of the liquid flowing through the interstage lines was estimated by the operators. The results, summarized in Figure C-2, give the average liquid level in each interstage line. The variability of the liquid level is $\pm 15 \%$ or less for all but one stage. Most stages showed a variability of only $\pm 5 \%$. The liquid level in the organic interstage line going from stage 31 to 32 had a variability of $\pm 30 \%$. As discussed in LEONARD-2002, the few high liquid levels could probably be eliminated with a contactor that was built with inlet ports that were tangential to the mixing zone of each stage. 


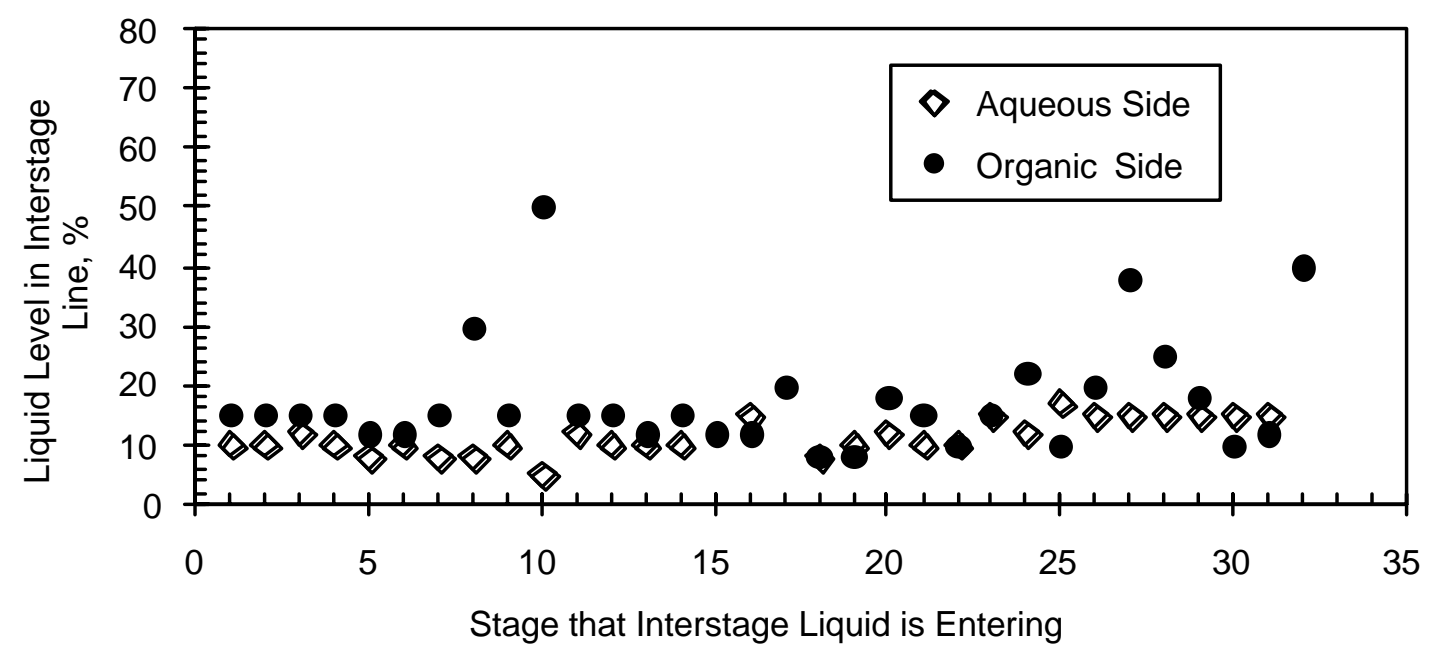

Fig. C-2. Average Liquid Levels during Test CS29

\section{Measurements after the Test}

After test CS29, the Cs concentration was measured for all available effluent samples. The results are listed in Table C-6 along with the DF concentration that is the basis value and the calculated decontamination, concentration, and stripping factors. Omitting the 5-min sample, the average Cs concentration is $3.6 \mathrm{E}-10 \pm 1.2 \mathrm{E}-10 \underline{\mathrm{M}}$ for the DW raffinate, $2.17 \mathrm{E}-03 \pm 0.18 \mathrm{E}-03 \underline{\mathrm{M}}$ for the EW effluent, $4.6 \mathrm{E}-10 \pm 2.6 \mathrm{E}-10 \underline{\mathrm{M}}$ for the FW effluent, and $3.7 \mathrm{E}-10 \pm 1.0 \mathrm{E}-10 \underline{\mathrm{M}}$ for the EP effluent. Several Cs concentrations were not available, as the samples were below the detection limit of the gamma counter for both counted samples. For these concentrations, "less than" values are reported. 
Table C-6. Effluent Concentrations during Test CS29

\begin{tabular}{|c|c|c|c|c|c|c|c|c|c|}
\hline Sample & $\begin{array}{c}\text { Time, } \\
\text { min }\end{array}$ & \begin{tabular}{|c|} 
Cs Conc. in \\
Aqueous \\
(DW) \\
Raffinate, \\
$\underline{M}$ \\
\end{tabular} & $\begin{array}{l}\text { Cs Conc. in } \\
\text { Aqueous } \\
\text { Strip (EW) } \\
\text { Effluent, } \underline{\mathrm{M}} \\
\end{array}$ & $\begin{array}{c}\text { Cs Conc. in } \\
\text { Aqueous } \\
\text { Wash (FW) } \\
\text { Effluent, } \underline{M}\end{array}$ & $\begin{array}{c}\text { Cs Conc. in } \\
\text { Organic } \\
\text { Strip (EP) } \\
\text { Effluent, } \underline{M}\end{array}$ & $\begin{array}{c}\text { Cs Conc. in } \\
\text { Aqueous } \\
\text { (DF) Feed, } \\
\underline{M}\end{array}$ & $\begin{array}{l}\text { Decon. } \\
\text { Factor, } \\
[\mathrm{DF}] / \mathrm{DW}]\end{array}$ & $\begin{array}{c}\text { Conc. } \\
\text { Factor, } \\
{[\mathrm{EW}] /} \\
{[\mathrm{DF}]} \\
\end{array}$ & $\begin{array}{c}\text { Stripping } \\
\text { Factor, } \\
{[\mathrm{DF}] /[\mathrm{EP}]}\end{array}$ \\
\hline 1 & 5 & $1.02 \mathrm{E}-10$ & $1.25 \mathrm{E}-03$ & $<1.58 \mathrm{E}-10$ & $4.83 \mathrm{E}-10$ & $1.40 \mathrm{E}-04$ & $1,368,425$ & 8.9 & 289,762 \\
\hline 2 & 30 & $2.58 \mathrm{E}-10$ & $2.10 \mathrm{E}-03$ & $1.21 \mathrm{E}-10$ & $3.49 \mathrm{E}-10$ & $1.40 \mathrm{E}-04$ & 541,777 & 15.0 & 401,336 \\
\hline 3 & 60 & $2.68 \mathrm{E}-10$ & $2.10 \mathrm{E}-03$ & $1.04 \mathrm{E}-09$ & $3.51 \mathrm{E}-10$ & $1.40 \mathrm{E}-04$ & 523,072 & 15.0 & 399,070 \\
\hline 4 & 90 & 2.92E-10 & & & & & & & \\
\hline 5 & 120 & $3.45 \mathrm{E}-10$ & $1.98 \mathrm{E}-03$ & $3.21 \mathrm{E}-10$ & $4.69 \mathrm{E}-10$ & $1.40 \mathrm{E}-04$ & 406,333 & 14.1 & 298,530 \\
\hline 6 & 180 & $4.32 \mathrm{E}-10$ & $2.04 \mathrm{E}-03$ & $5.94 \mathrm{E}-10$ & $5.50 \mathrm{E}-10$ & $1.40 \mathrm{E}-04$ & 323,826 & 14.6 & 254,476 \\
\hline 7 & 240 & & & & & & & 14.5 & 350,299 \\
\hline 8 & 300 & $3.34 \mathrm{E}-10$ & $2.11 \mathrm{E}-03$ & $<1.58 \mathrm{E}-10$ & $2.95 \mathrm{E}-10$ & $1.40 \mathrm{E}-04$ & 419,596 & 15.1 & 473,980 \\
\hline 9 & 360 & $3.59 \mathrm{E}-10$ & & & & & & 17.6 & 417,531 \\
\hline 10 & 420 & $3.64 \mathrm{E}-10$ & $2.38 \mathrm{E}-03$ & $6.51 \mathrm{E}-10$ & $1.61 \mathrm{E}-10$ & $1.40 \mathrm{E}-04$ & 384,598 & 17.0 & 869,286 \\
\hline 11 & 480 & $3.45 \mathrm{E}-10$ & $2.17 \mathrm{E}-03$ & $4.91 \mathrm{E}-10$ & $<3.4 \mathrm{E}-10$ & $1.40 \mathrm{E}-04$ & 406,333 & 15.5 & $>410,000$ \\
\hline 12 & 600 & $3.70 \mathrm{E}-10$ & $2.50 \mathrm{E}-03$ & $5.17 \mathrm{E}-10$ & $<1.45 \mathrm{E}-10$ & & & 17.8 & $>970,000$ \\
\hline 13 & 720 & $2.36 \mathrm{E}-10$ & $2.05 \mathrm{E}-03$ & $8.98 \mathrm{E}-11$ & $4.16 \mathrm{E}-10$ & $1.40 \mathrm{E}-04$ & 592,475 & 14.6 & 336,676 \\
\hline 14 & 810 & $7.30 \mathrm{E}-10$ & $2.28 \mathrm{E}-03$ & $5.09 \mathrm{E}-10$ & $4.06 \mathrm{E}-10$ & $1.40 \mathrm{E}-04$ & 191,691 & 16.3 & 344,888 \\
\hline
\end{tabular}

An overall Cs material balance for test CS29 was calculated using the flow rates and Cs concentrations for the incoming and outgoing process streams. The results, summarized in Table C-7, show that $112.0 \%$ of the Cs was recovered. Since the key values for the Cs material balance had standard deviations of $\pm 10.2 \%$ for the Cs concentration in DF, $\pm 8.0 \%$ for the Cs concentration in EW, $\pm 3.1 \%$ for the DF flow rate, and $\pm 4.4 \%$ for the EW flow rate, the standard deviation for the material balance is $\pm 14.0 \%$. Thus, within experimental error, there was $100 \%$ recovery of the Cs. 
Table C-7. Overall Material Balance for Cs during Test CS29

\begin{tabular}{|c|c|c|c|c|}
\hline $\begin{array}{l}\text { Stream } \\
\text { Identity }\end{array}$ & $\begin{array}{c}\text { Stream In or } \\
\text { Out }\end{array}$ & $\begin{array}{c}\text { Average Stream Flow } \\
\text { Rate, } \mathrm{mL} / \mathrm{min}\end{array}$ & $\begin{array}{c}\text { Average Stream Cs } \\
\text { Conc. , } \underline{\mathrm{M}}\end{array}$ & $\begin{array}{c}\text { Cs Flow, } \\
\text { millimoles/min }\end{array}$ \\
\hline $\mathrm{DF}$ & In & 40.08 & $1.40 \mathrm{E}-\overline{04}$ & 0.005610889 \\
\hline DS & In & 2.92 & 0 & 0.000000000 \\
\hline EF & In & 2.90 & 0 & 0.000000000 \\
\hline FF & In & 2.92 & 0 & 0.000000000 \\
\hline FX & In & 13.38 & $3.81 \mathrm{E}-10$ & 0.000000005 \\
\hline \multicolumn{4}{|c|}{ Total Cs Flow In, mM/min: } & 0.005610894 \\
\hline DW & Out & 43.0 & $3.61 \mathrm{E}-10$ & 0.000000016 \\
\hline EW & Out & 2.90 & $2.17 \mathrm{E}-03$ & 0.006285767 \\
\hline EP & Out & 13.38 & $3.81 \mathrm{E}-10$ & 0.000000005 \\
\hline $\mathrm{FW}$ & Out & 2.92 & 4.56E-10 & 0.000000001 \\
\hline \multicolumn{4}{|c|}{ Total Cs Flow Out, mM/min: } & 0.006285789 \\
\hline \multicolumn{4}{|c|}{ Amount of Cs recovered, $\%$ : } & 112.0 \\
\hline
\end{tabular}

Shortly after test CS29 was completed, the aqueous and organic liquids in each stage were drained and collected in $60-\mathrm{mL}$ polyethylene bottles. The stage samples were later equilibrated by shaking each collection bottle for 15-20 s. Immediately after equilibration, the sample temperature was measured. Then the two phases were separated and each phase was analyzed for its $\mathrm{Cs}$ concentration. These concentrations allow the apparent $\mathrm{D}_{\mathrm{Cs}}$ value to be calculated for each stage. These concentrations, temperatures, and $\mathrm{D}_{\mathrm{Cs}}$ values are given in Table C-8. Several Cs concentrations were not available (N/A), as the samples were below the detection limit of the gamma counter. Some of the concentrations and $\mathrm{D}_{\mathrm{Cs}}$ values in the scrub, strip, and wash sections are higher than expected based on the values seen in Table C-1. This is attributed to one or more of the following: (1) residual high concentrations of Cs in the stage drain lines, (2) residual high concentrations of either acid or base in the drain lines, (3) the lower equilibration temperatures. To get an idea of how well the stage samples represent actual stage conditions (when available), the average Cs concentration for the each effluent stream is also listed. 
Table C-8. Cs Concentration in Equilibrated Stage Samples from Test CS29

\begin{tabular}{|c|c|c|c|c|c|c|}
\hline $\begin{array}{c}\text { Stage } \\
\text { Number }\end{array}$ & $\begin{array}{c}\text { Cs Conc. } \\
\text { (Aqueous) after } \\
\text { Stage Sample } \\
\text { Equilibrated, } \underline{\underline{M}}\end{array}$ & $\begin{array}{c}\text { Cs Conc. } \\
\text { (Organic) after } \\
\text { Stage Sample } \\
\text { Equilibrated, M }\end{array}$ & $\begin{array}{l}\text { Equil. } \\
\text { Temp., } \\
{ }^{\circ} \mathrm{C}\end{array}$ & $D_{C s}$ & $\begin{array}{c}\text { Avg Cs Conc. } \\
\text { in Aqueous } \\
\text { Effluent } \\
\text { Samples, } \underline{\mathrm{M}} \\
\end{array}$ & $\begin{array}{l}\text { Avg Cs Conc. } \\
\text { in Organic } \\
\text { Effluent } \\
\text { Samples, } \underline{\mathrm{M}} \\
\end{array}$ \\
\hline 1 & N/A & $1.16 \mathrm{E}-09$ & 22.8 & N/A & $3.61 \mathrm{E}-10$ & \\
\hline 2 & $2.36 \mathrm{E}-10$ & $3.50 \mathrm{E}-09$ & 22.8 & 14.85 & & \\
\hline 3 & $5.81 \mathrm{E}-10$ & $8.94 \mathrm{E}-09$ & 22.8 & 15.39 & & \\
\hline 4 & $1.63 \mathrm{E}-09$ & $2.83 \mathrm{E}-08$ & 22.9 & 17.29 & & \\
\hline 5 & $3.55 \mathrm{E}-09$ & $6.50 \mathrm{E}-08$ & 23.1 & 18.32 & & \\
\hline 6 & 7.13E-09 & $1.31 \mathrm{E}-07$ & 22.9 & 18.41 & & \\
\hline 7 & $3.01 \mathrm{E}-08$ & 4.92E-07 & 23.0 & 16.36 & & \\
\hline 8 & $8.14 \mathrm{E}-08$ & $1.33 \mathrm{E}-06$ & 23.0 & 16.34 & & \\
\hline 9 & $1.62 \mathrm{E}-07$ & $2.66 \mathrm{E}-06$ & 23.4 & 16.42 & & \\
\hline 10 & 3.30E-07 & $6.10 \mathrm{E}-06$ & 23.3 & 18.46 & & \\
\hline 11 & $8.75 \mathrm{E}-07$ & $1.69 \mathrm{E}-05$ & 23.4 & 19.29 & & \\
\hline 12 & $2.36 \mathrm{E}-06$ & $4.30 \mathrm{E}-05$ & 24.2 & 18.25 & & \\
\hline 13 & $5.73 \mathrm{E}-06$ & $1.05 \mathrm{E}-04$ & 23.5 & 18.34 & & \\
\hline 14 & $1.35 \mathrm{E}-05$ & $2.19 \mathrm{E}-04$ & 23.9 & 16.30 & & \\
\hline 15 & $4.13 \mathrm{E}-05$ & $6.65 \mathrm{E}-04$ & 24.0 & 16.10 & & \\
\hline 16 & 4.63E-04 & 7.98E-04 & 22.7 & 1.725 & & \\
\hline 17 & $4.59 \mathrm{E}-04$ & 7.01E-04 & 22.7 & 1.528 & & \\
\hline 18 & $1.29 \mathrm{E}-03$ & 4.77E-04 & 22.8 & 0.369 & $2.17 \mathrm{E}-03$ & \\
\hline 19 & 5.04E-04 & $1.32 \mathrm{E}-04$ & 22.8 & 0.262 & & \\
\hline 20 & $1.55 \mathrm{E}-04$ & $2.72 \mathrm{E}-05$ & 22.7 & 0.175 & & \\
\hline 21 & $3.22 \mathrm{E}-05$ & $5.29 \mathrm{E}-06$ & 22.8 & 0.164 & & \\
\hline 22 & $6.46 \mathrm{E}-06$ & 1.06E-06 & 22.8 & 0.165 & & \\
\hline 23 & $1.18 \mathrm{E}-06$ & $2.39 \mathrm{E}-07$ & 22.8 & 0.203 & & \\
\hline 24 & 4.24E-07 & $4.82 \mathrm{E}-08$ & 23.1 & 0.114 & & \\
\hline 25 & 8.94E-08 & $1.31 \mathrm{E}-08$ & 22.7 & 0.146 & & \\
\hline 26 & $2.47 \mathrm{E}-08$ & $2.77 \mathrm{E}-09$ & 22.5 & 0.112 & & \\
\hline 27 & $8.87 \mathrm{E}-09$ & 1.09E-09 & 23.6 & 0.123 & & \\
\hline 28 & 3.35E-09 & N/A & 22.8 & N/A & & \\
\hline 29 & $1.82 \mathrm{E}-09$ & N/A & 23.5 & N/A & & \\
\hline 30 & $2.07 \mathrm{E}-09$ & $3.30 \mathrm{E}-10$ & 23.5 & 0.159 & & \\
\hline 31 & $2.88 \mathrm{E}-09$ & $3.15 \mathrm{E}-10$ & 23.1 & 0.109 & & \\
\hline 32 & $8.32 \mathrm{E}-10$ & N/A & 23.8 & N/A & & $3.81 \mathrm{E}-10$ \\
\hline 33 & N/A & $8.44 \mathrm{E}-10$ & 24.3 & N/A & $4.56 \mathrm{E}-10$ & \\
\hline
\end{tabular}

The concentrations of Cs in both phases of each stage at the end of test CS29 can be calculated using the SASSE model [LEONARD-1994]. The procedure for doing this for the CSSX process at a given temperature is given in LEONARD-2001D. The effect of temperature on the $\mathrm{D}_{\mathrm{Cs}}$ values for the CSSX solvent was added by using information from BONNESEN- 
2000. The enthalpy $(\mathrm{H})$ for this $\mathrm{Cs}$ extraction reaction is obtained from the slope of each curve in Figure 5 of BONNESEN-2000. It is $42.8 \mathrm{~kJ} / \mathrm{mol}$ for the extraction section, $61.8 \mathrm{~kJ} / \mathrm{mol}$ for the scrub section, and $62.5 \mathrm{~kJ} / \mathrm{mol}$ for the strip section. This means that, going from 20 to $30^{\circ} \mathrm{C}, \mathrm{D}_{\mathrm{Cs}}$ will drop by $1.79 \times$ in the extraction section, $2.31 \times$ in the scrub section, and $2.33 \times$ in the strip section. The equation for $D_{C s}$ that gives $D_{1}$ at $T_{1}$ knowing $D_{0}$ at $T_{0}$ is

$$
\mathrm{D}_{1}=\mathrm{D}_{0} * \exp \left[(\mathrm{H} / \mathrm{R}) *\left\{\left(1 / \mathrm{T}_{1}\right)-\left(1 / \mathrm{T}_{0}\right)\right\}\right],
$$

where $\mathrm{T}$ is the absolute temperature in $\mathrm{K}, \mathrm{H}$ is as given above in $\mathrm{kJ} / \mathrm{mol}$, and $\mathrm{R}$ is $0.0083144 \mathrm{~kJ} /(\mathrm{mol} \cdot \mathrm{K})$. Using the temperature data above, the liquids flowing through the stages were estimated to be $26.7^{\circ} \mathrm{C}$ in stages $1-13,25.3^{\circ} \mathrm{C}$ in stage $14,23.9^{\circ} \mathrm{C}$ in stage $15,27.0^{\circ} \mathrm{C}$ in stages $16-17,30.2^{\circ} \mathrm{C}$ in stage $18,31.2^{\circ} \mathrm{C}$ in stage $19,33.2^{\circ} \mathrm{C}$ in stages $20-30,31.5^{\circ} \mathrm{C}$ in stage 31 , and $30.8^{\circ} \mathrm{C}$ in stage 32 . Stage 33 was omitted from the model. In the SASSE calculations, the effect of diluent loss is included by increasing the no-load $\mathrm{D}_{\mathrm{Cs}}$ values for the extraction and scrub sections and the $\mathrm{D}_{\mathrm{Cs}}$ value at low concentrations in the strip section (see Table C-1) by $5.1 \%$. Using the SASSE model with solvent recycle and the stage-to-stage concentration profile for Cs given in Table $\mathrm{C}-8$, the best fit of the model to the data was found to be for a stage efficiency of $85 \%$ in the extraction section and $92 \%$ in the strip section. As can be seen in Figure C-3, the model is in reasonable agreement with the measured Cs concentrations. In the multiday test CS27 described in LEONARD-2002, the measured Cs concentrations at the end of the extraction section (stages 1-6) flatten out, while the model indicated the Cs concentration should continue to fall for several more stages. For test CS29, the model matched the measured Cs concentrations down to the end (stage 1). This is attributed to the extra care taken to get the unit clean. There is a similar good match for the strip section from stages 18 to 27 . For stages 28 to 32, the measured Cs concentrations level out. Cleaning was less rigorous for the strip section, with only water being used. The $1 \underline{\mathrm{M}} \mathrm{HNO}_{3}$ cleaning solutions were not used, as they would then have to be completely removed to avoid compromising the operation of the strip section. The measured Cs concentrations for many strip stages seemed too high for the multiday test [LEONARD-2002]. This was attributed to contamination of the strip-stage drain lines during the process upset late in the test. For test CS29, where there was no process upset and the unit was well cleaned, the measured Cs concentrations follow the model until stage 28. Further cleaning would not have been especially useful, as the Cs concentrations were approaching and in some cases falling below the detection limit of the gamma counter. 


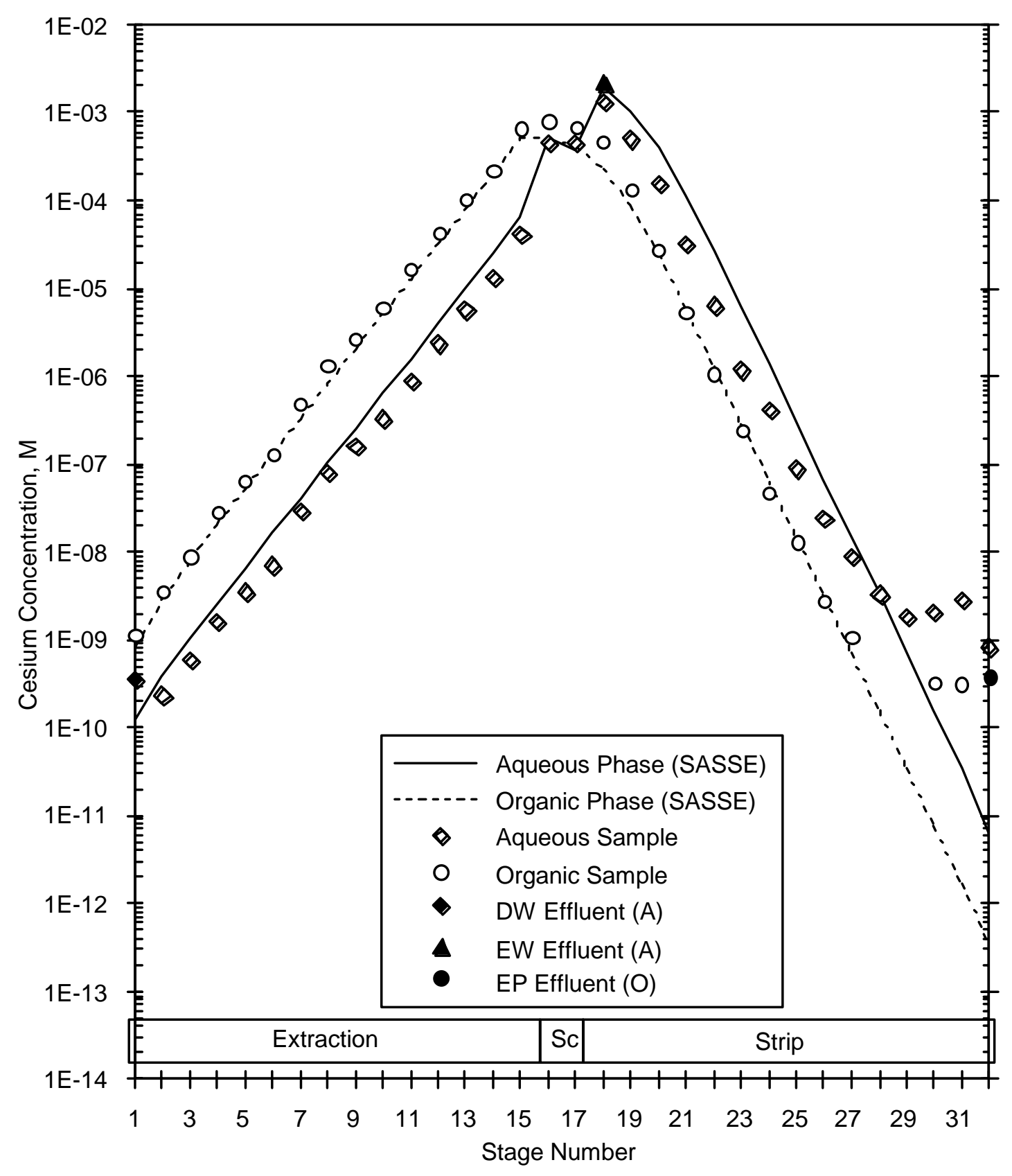

Fig. C-3. Cs Concentration Profile at End of Test CS29

\section{Diluent Loss Rate}

Calculations were made to see if the diluent loss rate from the solvent is consistent with the estimated diluent vapor pressure. The diluent loss rate was $0.48 \mathrm{~mL} / \mathrm{min}$ for test CS28 (see Section 2 in Appendix B) and $0.05 \mathrm{~mL} / \mathrm{min}$ for test CS29 (see Section 3 in this appendix). Based on the discussion in this appendix, the diluent rate for test CS29 is probably a more typical value for the CSSX process in the 2-cm contactor. The vapor pressure for Isopar L was estimated by 
assuming that the vapor pressure is proportional to the evaporation rate. The evaporation rate for Isopar $\mathrm{L}$ is given as 3 relative to 100 for n-butyl acetate on the 2001 Exxon Mobil Chemical data sheet for Isopar L. The vapor pressure for n-butyl acetate at $20^{\circ} \mathrm{C}$ is given as $1040 \mathrm{~Pa}$ (7.8 torr) on the 2000 solvent physical properties sheet from Honeywell Burdick \& Jackson, Muskegon, Michigan. Using this information, the vapor pressure for Isopar $\mathrm{L}$ at $20^{\circ} \mathrm{C}$ is estimated to be 31 Pa. From a correlation in REID-1958, it appears that the vapor pressure of hydrocarbons such as Isopar $\mathrm{L}$ will double for every $10^{\circ} \mathrm{C}$ rise in temperature. Thus, at $40^{\circ} \mathrm{C}$, the temperature of the contactor stage blocks in the strip section (see Table C-1), the vapor pressure for Isopar L is estimated to be $124 \mathrm{~Pa}$. These vapor-pressure calculations neglect the effect of the other solvent components on the vapor pressure of Isopar L. For comparison with the estimated vapor pressure for Isopar L, an apparent vapor pressure can be calculated from the diluent loss rate for test CS29 $(0.05 \mathrm{~mL} / \mathrm{min})$ if the amount of gas (air) passing through the contactor is known. Based on the purge gas flow alone, which is $1.4 \mathrm{~L} / \mathrm{min}$, the apparent vapor pressure for Isopar $\mathrm{L}$ is $362 \mathrm{~Pa}$. Based on past experience (that is, the exit tubes for the less-dense phase in the rotor body can pump a considerable amount of gas out of the contactor), one author (Leonard) estimated that the gas pumped out with the EP effluent could be $2.3 \mathrm{~L} / \mathrm{min}$. When this is combined with the purge gas flow, the apparent vapor pressure for Isopar $\mathrm{L}$ is $137 \mathrm{~Pa}$. If there is a small amount of additional gas flow out the three aqueous effluent ports (DW, EW, and $\mathrm{FW}$ ) where the rotor does not pump gas as efficiently $(0.4 \mathrm{~L} / \mathrm{min})$, the apparent vapor pressure for Isopar $\mathrm{L}$ is $124 \mathrm{~Pa}$. This last scenario, which matches the estimated vapor pressure for Isopar $\mathrm{L}$ at $40^{\circ} \mathrm{C}$, indicates that, with the higher temperatures in the contactor and reasonable estimates of gas (air) flow through the contactor, the observed diluent losses could be explained for test CS29.

If this simple model to explain the rate of diluent loss is correct, then diluent loss can be reduced by limiting the flow of gas (air) through the contactor. One way to do this would be to extend the effluent lines far enough below the surface of the tank liquid to keep any gas from being pumped out. This was not done during the CSSX flowsheet tests to allow effluent samples to be taken. The lines all stopped above the liquid surface of the effluent tanks. If all lines for exiting liquids are below the liquid surface in the effluent tanks, the gas flow through the contactor should be limited to the flow of the purge gas. Based on the diluent-loss model, this would have reduced the rate of diluent loss from the 2 -cm contactor by a factor of three. Note that, while the effluent lines are sealed by the liquid in the effluent tanks, the effluent tanks themselves must not be sealed. If they are sealed, the entering liquid pressurizes the gas in the tank. When the pressure is high enough, liquid will be prevented from flowing out of the contactor and the contactor will become inoperable until the tank is vented. 


\section{REFERENCES}

\section{BONNESEN-1998}

P. V. Bonnesen, L. H. Delmau, T. J. Haverlock, and B. A. Moyer, Alkaline-Side Extraction of Cesium from Savannah River Tank Waste using a Calixarene-Crown Ether Structure, Oak Ridge National Laboratory Report ORNL/TM-13704 (1998).

\section{BONNESEN-2000}

P. V. Bonnesen, L. H. Delmau, B. A. Moyer, and R. A. Leonard, "A Robust AlkalineSide CSEX Solvent Suitable for Removing Cesium from Savannah River High Level Waste," Sol. Extr. Ion Exch. 18(6), 1079-1107 (2000)

\section{DELMAU-2002}

L. H. Delmau and F. V. Sloop, Jr., Oak Ridge National Laboratory, unpublished data (2002).

KLATT-2002

L. N. Klatt, J. F. Birdwell, P. V. Bonnesen, L. H. Delmau, L. J. Foote, D. D. Lee, R. A. Leonard, T. G. Levitskaia, M. P. Maskarinec, and B. A. Moyer, Caustic-Side Solvent Extraction Solvent-Composition Recommendations, Oak Ridge National Laboratory Report ORNL/TM-2001/258 (January 2002).

LEONARD-1994

R. A. Leonard and M. C. Regalbuto, "A Spreadsheet Algorithm for Stagewise Solvent Extraction," Sol. Extr. Ion Exch. 12(5), 909-930 (1994).

\section{LEONARD-1999}

R. A. Leonard, C. Conner, M. W. Liberatore, J. Sedlet, S. B. Aase, and G. F. Vandegrift, Evaluation of an Alkaline-Side Solvent Extraction Process for Cesium Removal from SRS Tank Waste Using Laboratory-Scale Centrifugal Contactors, Argonne National Laboratory Report ANL-99/14 (1999).

\section{LEONARD-2000}

R. A. Leonard, S. B. Aase, H. A. Arafat, C. Conner, J. R. Falkenberg, and G. F. Vandegrift, Proof-of-Concept Flowsheet Tests for Caustic-Side Solvent Extraction of Cesium from Tank Waste, Argonne National Laboratory Report ANL-00/30 (2000).

\section{LEONARD-2001A}

R. A. Leonard, S. B. Aase, H. A. Arafat, C. Conner, J. R. Falkenberg, and G. F. Vandegrift, Development of an Improved 2-cm Centrifugal Contactor for Cesium Removal from High-Level Waste, Argonne National Laboratory Report ANL-01/23 (2001). 
LEONARD-2001B

R. A. Leonard, S. B. Aase, H. A. Arafat, D. B. Chamberlain, C. Conner, M. C. Regalbuto, and G. F. Vandegrift, Interim Report on a Multi-Day Test of the Caustic-Side Solvent Extraction Flowsheet for Cesium Removal from a Simulated SRS Tank Waste, Argonne National Laboratory Report ANL-01/10 (2001).

LEONARD-2001C

R. A. Leonard, M. C. Regalbuto, S. B. Aase, H. A. Arafat, and J. R. Falkenberg, Hydraulic Performance of a 5-cm CINC Contactor for Caustic-Side Solvent Extraction, Argonne National Laboratory Letter Report ANL/CMT/CSSX-2001/06 (2001). This report is being prepared for issue as Argonne National Laboratory Report ANL-02/18 (2001).

LEONARD-2001D

R. A. Leonard, Caustic-Side Solvent Extraction for Optimized Solvent, Argonne National Laboratory Letter Report ANL/CMT/CSSX-2001/07 (2001). This report is being prepared for issue as Argonne National Laboratory Report ANL-02/19 (2001).

LEONARD-2002

R. A. Leonard, S. B. Aase, H. A. Arafat, D. B. Chamberlain, C. Conner, J. R. Falkenberg, M. C. Regalbuto, and G. F. Vandegrift, Multi-Day Test of the Caustic-Side Solvent Extraction Flowsheet for Cesium Removal from a Simulated SRS Tank Waste, Argonne National Laboratory Report ANL-02/11 (2002).

\section{LEVENSON-2000}

M. Levenson, et al., Alternatives for High-Level Waste Salt Processing at the Savannah River Site, National Research Council, National Academy Press, Washington, DC (2000).

\section{PETERSON-2000}

R. A. Peterson, Preparation of Simulated Waste Solutions for Solvent Extraction Testing, Westinghouse Savannah River Co. Report WSRC-RP-2000-361 (May 1, 2000).

REID-1958

R. C. Reid and T. K. Sherwood, The Properties of Gases and Liquids: Their Estimation and Correlation, McGraw-Hill, New York (1958).

WALKER-1998

D. D. Walker and G. K. Georgeton, Viscosity and Density of Simulated Salt Solutions, Westinghouse Savannah River Company Report WSRC-RP-89-1088 (October 19, 1989). 


\section{Distribution List for ANL-02/22}

Internal (Printed and Electronic Copies):
S. B. Aase
E. Freiberg
M. C. Regalbuto (5)
H. A. Arafat
A. V. Guelis
M. J. Steindler
A. J. Bakel
J. E. Helt
D. B. Chamberlain
R. A. Leonard (5)
G. F. Vandegrift
Y. I. Chang
D. Lewis (2)
M. L. Dietz
K. L. Nash
S. K. Zussman

Internal (Electronic Copy Only):

TIS Files

D. L. Bowers

R. J. Finch

E. C. Gay

C. J. Mertz

J. Sedlet

\section{External (Printed and Electronic Copies):}

Chemical Technology Division Review Committee Members:

H. U. Anderson, University of Missouri-Rolla, Rolla, MO

R. A. Greenkorn, Purdue University, West Lafayette, IN

C. L. Hussey, University of Mississippi, University, MS

M. V. Koch, University of Washington, Seattle, WA

V. P. Roan, Jr., University of Florida, Gainesville, FL

J. R. Selman, Illinois Institute of Technology, Chicago, IL

J. S. Tulenko, University of Florida, Gainesville, FL

J. F. Birdwell, Oak Ridge National Laboratory, Oak Ridge, TN

P. V. Bonnesen, Oak Ridge National Laboratory, Oak Ridge, TN

S. G. Campbell, Westinghouse Savannah River Company, Aiken, SC

J. T. Carter, Westinghouse Savannah River Company, Savannah River Technology Center, Aiken, SC

C. Conner, BWX Technologies, Inc., Lynchburg, VA

L. H. Delmau, Oak Ridge National Laboratory, Oak Ridge, TN

H. D. Harmon, Westinghouse Savannah River Company, Aiken, SC

R. T. Jubin, Oak Ridge National Laboratory, Oak Ridge, TN

J. D. Law, Idaho National Engineering and Environmental Laboratory, Research Center, Idaho Falls, ID

R. Leugemors, Pacific Northwest National Laboratory, Richland, WA

G. J. Lumetta, Battelle, Pacific Northwest National Laboratory, Richland, WA

B. A. Moyer, Oak Ridge National Laboratory, Oak Ridge, TN

M. Norato, Westinghouse Savannah River Company, Aiken, SC 
R. A. Pierce, Westinghouse Savannah River Company, Aiken, SC

P. C. Suggs, DOE-SR, Aiken, SC

M. C. Thompson, Westinghouse Savannah River Company, Savannah River Technology Center, Aiken, SC

T. A. Todd, Idaho National Engineering and Environmental Laboratory, Idaho Falls, ID

D. D. Walker, Westinghouse Savannah River Company, Aiken, SC

\section{External (Printed Copy Only):}

Tanks Focus Area Technical Team, c/o B. J. Williams, Pacific Northwest National Laboratory, Richland, WA

Tanks Focus Area Field Lead, c/o T. P. Pietrok, DOE, Richland Operations Office, Richland, WA

Tanks Focus Area Headquarters Program Manager, c/o K. D. Gerdes, DOE-EM,

Germantown, MD

External (Electronic Copy Only):

ANL-E-Library

ANL-W-Library

DOE-OSTI

W. D. Clark, DOE-SR, Aiken, SC

S. M. Dinehart, Los Alamos National Laboratory, Los Alamos, NM

R. E. Edwards, Westinghouse Savannah River Company, Aiken, SC

S. D. Fink, Westinghouse Savannah River Company, Aiken, SC

L. N. Klatt, Oak Ridge National Laboratory, Oak Ridge, TN

D. E. Kurath, Battelle, Pacific Northwest National Laboratory, Richland, WA

K. T. Lang, USDOE, Washington, DC

J. W. McCullough, USDOE, Aiken, SC

C. P. McGinnis, Oak Ridge National Laboratory, Oak Ridge, TN

M. Miles, Oak Ridge National Laboratory, Oak Ridge, TN

A. L. Olson, Idaho National Engineering and Environmental Laboratory, Idaho Falls, ID

M. J. Palmer, Los Alamos National Laboratory, Los Alamos, NM

L. M. Papouchado, Westinghouse Savannah River Company, Aiken, SC

R. A. Peterson, Bechtel-Washington Process Technology, Richland, WA

B. M. Rapko, Battelle, Pacific Northwest National Laboratory, Richland, WA

R. D. Rogers, University of Alabama, Tuscaloosa, AL

K. J. Rueter, Bechtel-Washington Process Technology, Richland, WA

P. Rutland, Bechtel-Washington Process Technology, Richland, WA

S. N. Schlahta, Battelle, Pacific Northwest National Laboratory, Richland, WA

J. L. Swanson, Richland, WA

W. L. Tamosaitis, Westinghouse Savannah River Company, Aiken, SC

L. L. Tavlarides, Syracuse University, Syracuse, NY

D. W. Tedder, Georgia Institute of Technology, Atlanta, GA

V. Van Brunt, University of South Carolina, Columbia, SC 
J. F. Walker, Oak Ridge National Laboratory, Oak Ridge, TN

J. S. Watson, Oak Ridge National Laboratory, Oak Ridge, TN

R. M. Wham, Oak Ridge National Laboratory, Oak Ridge, TN

V. Wheeler, Oak Ridge National Laboratory, Oak Ridge, TN

W. R. Wilmarth, Westinghouse Savannah River Company, Aiken, SC 